\title{
A novel pyruvate kinase (PK-S) from boar spermatozoa is localized at the fibrous sheath and the acrosome
}

\author{
Sandra Feiden, Heike Stypa, Uwe Wolfrum', Gerhard Wegener and Günter Kamp \\ Molecular Physiology Section, Institute of Zoology and ${ }^{1}$ Cell and Matrix Biology Section, Johannes Gutenberg- \\ University, Becherweg 9-11, D-55099 Mainz, Germany \\ Correspondence should be addressed to G Kamp; Email: kamp@uni-mainz.de
}

\begin{abstract}
Boar spermatozoa contain a novel pyruvate kinase (PK-S) that is tightly bound at the acrosome of the sperm head and at the fibrous sheath in the principal piece of the flagellum, while the midpiece contains a soluble pyruvate kinase (PK). PK-S could not be solubilized by detergents, but by trypsin with no loss of activity. Purified PK-S as well as PK-S still bound to cell structures and soluble sperm PK have all kinetics similar to those of rabbit muscle PK-M1. The PK-S subunit had a relative molecular mass of $64 \pm$ $1 \times 10^{3}(n=3)$, i.e. slightly higher than that of PK-M1, and carried an N-terminal extension $\left(\mathrm{NH}_{2}-\mathrm{TSEAM}^{\mathrm{COOH}}\right)$ that is lacking in native PK-M1. Evidence is provided that PK-S is encoded by the PKM gene. Antibodies produced against the N-terminus of purified PK-S ( $\mathrm{NH}_{2}$-TSEAMPKAHMDAG-COOH) were specific for PK-S as they did not react with somatic PKs or soluble sperm PK, while anti-PK-M1 recognized both sperm PKs. Immunofluorescence microscopy showed anti-PK-S to label the acrosome and the flagellar principal piece, whereas the midpiece containing the mitochondria was labelled only by anti-PK-M1. Immunogold labelling confirmed the localization of PK-S at the acrosome. In the principal piece, both polyclonal anti-PK-M1 and anti-PK-S were found at the fibrous sheath. Our results suggest that PK-S is a major component in the structural organization of glycolysis in boar spermatozoa.
\end{abstract}

Reproduction (2007) 134 81-95

\section{Introduction}

Mammalian spermatozoa are elongated and polarized motile cells with functionally different compartments. The head contains the nucleus with condensed chromatin which has to be transferred to an egg for fertilization. At the front part, the nucleus is covered by the acrosome which releases hydrolytic enzymes to facilitate penetration of the zona pellucida of an egg. The flagellum harbours the central axoneme with the machinery for swimming. Its dynein-ATPases hydrolyse ATP to ADP and inorganic phosphate thus providing free energy for flagellar beating. The axoneme is surrounded by dense fibres which probably improve stability and elasticity of the flagellum. The sperm head is connected to the relatively short midpiece of the flagellum where all sperm mitochondria are concentrated surrounding the dense fibres. The principal piece lacks mitochondria but contains the fibrous sheath, a structure typical for mammalian (Fouquet \& Kann 1994) and some reptilian (Jamieson et al. 1996) spermatozoa. It appears segmented by semi-circular ribs connecting two longitudinal columns thus providing flagellar flexibility.

Mammalian spermatozoa use extracellular sugars as the main substrate for ATP production (Mann \& Lutwak-Mann 1981, Kamp et al. 1996, Marin et al. 2003), but species-specific differences have been reported (Rodriguez-Gil 2006). Glycolysis seems to be essential for fertilization in sperm of mouse, rat, hamster and man but not in bovine sperm (Miki et al. 2004, Galantino-Homer et al. 2004). The mechanisms by which glycolysis affects fertility of spermatozoa remain still not clear. Glycolysis is involved in capacitation by stimulation of protein tyrosine phosphorylation (Urner \& Sakkas 2003) and/or in providing the principal piece of the flagellum with ATP particularly for the vigorous whiplash motility (hyperactivity) that produces the thrust to penetrate the zona pellucida (Yanagimachi 1994, Bedford 1998, Bone et al. 2000, Williams \& Ford 2001). Whether local glycolytic ATP-production is essential for sperm motility or can be substituted by other means has comprehensively been discussed by Ford (2006). Several glycolytic enzymes show unusual properties, suggesting that glycolysis in the principal 
piece is structurally organized along the fibrous sheath of the flagellum (Visconti et al. 1996, Westhoff \& Kamp 1997, Bunch et al. 1998, Travis et al. 1998, Krisfalusi et al. 2006). Sperm specific isozymes are known for hexokinase (HK1-S; Travis et al. 1998) and glyceraldehyde 3-phosphate dehydrogenase in mice (GAPDH-S; Bunch et al. 1998). HK1-S and GAPDH-S possess unique $\mathrm{N}$-terminal amino acid sequences which probably anchor the enzymes to sperm structures (see Eddy et al. 2003). In the flagellum of boar sperm, GAPDH is located along the fibrous sheath, whereas it could not be detected in the midpiece (Westhoff \& Kamp 1997) probably because it had been removed by maturating sperm in cytoplasmic droplets together with the endoplasmic reticulum. Release of GAPDH from sedimented sperm fragments required tryptic digestion. In contrast, HK1-S was located not only at the fibrous sheath, but also at mitochondria and at membranes of the head, and unlike GAPDH it was solubilized by detergents like Triton X-100 (Travis et al. 1998).

Association with sperm structures had also been reported of pyruvate kinase (PK, EC 2.7.1.40) the last enzyme of glycolysis. PK of rabbit spermatozoa could not be washed out from hypotonically treated sperm, although its catalytical properties were similar to those of muscle PK (PK-M1), which is a soluble enzyme (Storey \& Kayne 1980). Recently Krisfalusi et al. (2006) have demonstrated that $\mathrm{PK}$ is bound to the purified fibrous sheath of mouse spermatozoa. However, it is not known whether spermatozoa contain a somatic and/or a spermspecific PK form and whether PK is located exclusively at the fibrous sheath. Moreover, it is still an open question by which type of binding PK is attached to sperm structures. The physiological functions of the PK-binding are also not clear. Does it serve the spatial organization of glycolysis in sperm or does it affect the kinetics of the enzyme or both?

In order to answer some of these questions we have purified the bound PK from ejaculated boar sperm and produced specific antibodies against its $\mathrm{N}$-terminal amino acid sequence. Using these antibodies and polyclonal anti-PK-M1, we have studied whether boar spermatozoa contain different PKs and where these are localized. Furthermore, we have tested whether the kinetics of PK from boar spermatozoa differ from those of somatic PKs.

\section{Materials and Methods}

\section{Samples and chemicals}

Fresh ejaculates from fertile boars diluted tenfold with Beltsville thawing solution (BTS) were provided by a breeder association (59387 Ascheberg, Germany) and swine tissues as well as blood from a local butcher. Goat antibodies against PK from rabbit muscle (anti-PK-M1) were obtained from DPC Biermann (61231 Bad Nauheim,
Germany), peroxidase-conjugated secondary antibodies from Sigma-Aldrich Inc., fluorescence-labelled secondary antibodies from Molecular Probes (2333 AA Leiden, The Netherlands) and gold-labelled secondary antibodies from Aurion (6702 AA Wageningen, The Netherlands).

Biochemicals and enzymes were obtained from Roche Diagnostics $\mathrm{GmbH}$ (68305 Mannheim, Germany) and Sigma-Aldrich Inc. Fractogel $\mathrm{EMD} \mathrm{SO}_{3}^{-}(\mathrm{S})$ and Fractogel EMD Propyl (S) as well as other chemicals were purchased from Merck KGaA (64271 Darmstadt, Germany), RotiLoad 1, Roti-Block and glycerol from Carl Roth GmbH and Co. (76185 Karlsruhe, Germany) and the nitrocellulose membrane (Protran BA 85 Cellulosenitrate) from Schleicher and Schuell (37582 Dassel, Germany). Amersham Biosciences Europe GmbH (79111 Freiburg, Germany) provided standard proteins low molecular weight (LMW), Bio-Rad Laboratories GmbH (80939 München, Germany) the Bio-Rad Protein Assay (dye reagent concentrate). Ovalbumin and Tween 20 were purchased from AppliChem GmbH (64291 Darmstadt, Germany) and phenylmethylsulfonyl fluoride (PMSF), cold-water fish gelatine as well as 4'-6-diamidino-2-phenylindol and LR White acrylic resins from Sigma-Aldrich Inc. Other chemicals were obtained from Sigma-Aldrich Inc. and Serva Electrophoresis $\mathrm{GmbH}$ (69115 Heidelberg, Germany). Mounting media Mowiol was obtained from Hoechst (65926 Frankfurt, Germany).

\section{Enzyme activity assays}

Activities of PK (EC 2.7.1.40) and GAPDH (EC 1.2.1.12) were measured using coupled assays with $\mathrm{NADH}_{2}$ as indicator (Bergmeyer 1983) at $25^{\circ} \mathrm{C}$ and $\mathrm{pH}$ 7.6. The assay for $\mathrm{PK}$ comprised $50 \mathrm{mmol} / \mathrm{l}$ triethanolamine (TRA), $50 \mathrm{mmol} / \mathrm{I} \mathrm{KCl}, 4 \mathrm{mmol} / \mathrm{l} \mathrm{MgCl}_{2}, 0.2 \mathrm{mmol} / \mathrm{l}$ $\mathrm{NADH}_{2}, \quad 1 \mathrm{mmol} / \mathrm{l}$ phosphoenolpyruvate (PEP), $1 \mathrm{mmol} / \mathrm{l}$ ADP, lactate dehydrogenase $(4 \mathrm{U} / \mathrm{ml})$; for GAPDH $50 \mathrm{mmol} / / \mathrm{TRA}, 1 \mathrm{mmol} / \mathrm{I}$ EDTA, $4 \mathrm{mmol} / \mathrm{l}$ $\mathrm{MgSO}_{4}, 2.4 \mathrm{mmol} / /$ glutathione (reduced), $0.2 \mathrm{mmol} / \mathrm{l}$ $\mathrm{NADH}_{2}, 1 \mathrm{mmol} / \mathrm{l}$ ATP, $7 \mathrm{mmol} / \mathrm{l}$ 3-phosphoglycerate, phosphoglycerate kinase $(10 \mathrm{U} / \mathrm{ml})$. If PK was measured in samples (e.g. extracts) containing adenylate kinase, its specific inhibitor diadenosine pentaphosphate $\left(\mathrm{AP}_{5} \mathrm{~A}\right)$ was added (10 $\mu \mathrm{mol} / \mathrm{l}$ final concentration). The assays of enzyme activity were verified by testing whether the amount of substrate transformed was linear with the amount of enzyme. Enzyme activities are given as $U$ ( $\mu \mathrm{mol}$ of substrate transformed per minute, $25^{\circ} \mathrm{C}$ ) together with S.D. ( \pm s.D.) and the number $n$ of independent measurements.

\section{Extraction of PK from spermatozoa}

Boar spermatozoa were separated from seminal plasma and BTS by centrifugation $\left(3000 \mathrm{~g} ; 17^{\circ} \mathrm{C}\right.$, 
$15 \mathrm{~min}$ ) and stored at $-20^{\circ} \mathrm{C}$. Thawed sperm were resuspended in $10 \mathrm{ml} / \mathrm{g}$ buffer $(\mathrm{pH}$ 7.3) comprising $25 \mathrm{mmol} / \mathrm{l}$ sodium phosphate, $1 \mathrm{mmol} / \mathrm{l}$ EDTA and $1 \mathrm{mmol} / \mathrm{l}$ dithiothreitol (DTT). Sperm were disrupted by sonication (Branson Sonifier, $6 \times 6 \mathrm{~s}$ with intermittent cooling). The crude homogenate was centrifuged $\left(10000 \mathrm{~g} ; 4{ }^{\circ} \mathrm{C} ; 4 \mathrm{~min}\right)$ and the supernatant discarded. The sediment was washed twice in the same buffer, sonicated and centrifuged as before. Finally the sediment was resuspended in sodium phosphate buffer $(10 \mathrm{mmol} / \mathrm{l} ; 1 \mathrm{mmol} / \mathrm{l}$ EDTA, $1 \mathrm{mmol} / \mathrm{I} \mathrm{DTT} ; \mathrm{pH} 7.3$ ) and incubated with trypsin (3 mg/g sperm wet weight) at room temperature for $5 \mathrm{~min}$. Trypsin was then inhibited by adding $20 \mu \mathrm{l}$ of $0.1 \mathrm{~mol} / \mathrm{l} \mathrm{PMSF}$ per gram of sperm. The sample was immediately centrifuged at $40000 \mathrm{~g}$ at $4{ }^{\circ} \mathrm{C}$ for $20 \mathrm{~min}$. The supernatant was used for purification of the proteolytically solubilized PK (PK-S).

\section{Purification of PK-S}

The solubilized PK was purified by ion exchange and hydrophobic interaction chromatography. The supernatant containing PK was adjusted to $\mathrm{pH} 7.15$ and applied to a column of Fractogel EMD $\mathrm{SO}_{3}^{-}$(S) (bed volume $10 \mathrm{ml}$, flow rate $2 \mathrm{ml} / \mathrm{min}$ ) that had been equilibrated with sodium phosphate buffer $(10 \mathrm{mmol} / \mathrm{l}$; $\mathrm{pH} 7.15)$ containing $1 \mathrm{mmol} / \mathrm{l}$ DTT and $10 \%(\mathrm{v} / \mathrm{v})$ glycerol. The column was extensively rinsed overnight with the same buffer. Proteins were eluted by increasing the phosphate concentration stepwise first to $15 \mathrm{mmol} / \mathrm{l}$ (flow rate $3 \mathrm{ml} / \mathrm{min}$ ), then to $38 \mathrm{mmol} / \mathrm{l}$ (flow rate $5 \mathrm{ml} / \mathrm{min}$ ). The activities of PK and GAPDH were determined in fractions of $5 \mathrm{ml}$ (in the $15 \mathrm{mmol} / \mathrm{l}$ eluate) and $3 \mathrm{ml}$ (in the $38 \mathrm{mmol} / \mathrm{l}$ eluate). The fractions of the main $\mathrm{PK}$ peak were combined and adjusted to $\mathrm{pH} 7.3$ and $30 \%(\mathrm{w} / \mathrm{v}) ;\left(\mathrm{NH}_{4}\right)_{2} \mathrm{SO}_{4}$. The sample was then applied to a column of Fractogel EMD Propyl (S) (bed volume $10 \mathrm{ml}$, flow rate $2 \mathrm{ml} / \mathrm{min}$ ) that had been equilibrated with sodium phosphate buffer $(25 \mathrm{mmol} / \mathrm{l} ; \mathrm{pH}$ 7.3) containing $1 \mathrm{mmol} / \mathrm{I} \mathrm{EDTA}$ and $1 \mathrm{mmol} / \mathrm{I}$ DTT as well as $30 \%(\mathrm{w} / \mathrm{v})\left(\mathrm{NH}_{4}\right)_{2} \mathrm{SO}_{4}$ and $10 \%(\mathrm{v} / \mathrm{v})$ glycerol. The column was extensively rinsed overnight with the same buffer. Proteins were eluted by reducing the $\left(\mathrm{NH}_{4}\right)_{2} \mathrm{SO}_{4}$ concentration stepwise to 20.5, 19.5, 14, 12.5 and $11 \%$ (flow rate $2 \mathrm{ml} / \mathrm{min}$ ). Activities of PK and GAPDH were measured in fractions of $5 \mathrm{ml}$ (in the $20.5 \%$ eluates) and $2 \mathrm{ml}$ (in the 19.5, 14, 12.5 and $11 \%$ eluates). Protein was determined according to Bradford (1976). The final purification was assessed with respect to specific activity, purification factor and PK yield as well as by SDS-PAGE.

\section{Extraction of PK from boar tissues and erythrocytes}

Fresh tissues were generally homogenized in 10 volumes $(\mathrm{v} / \mathrm{w})$ but in case of kidney in 2.5 volumes of sodium phosphate buffer $(50 \mathrm{mmol} / \mathrm{l} ; 1 \mathrm{mmol} / \mathrm{I}$ EDTA, $1 \mathrm{mmol} / \mathrm{l}$ DTT; pH 7.3) using an Ultra Turrax $(6 \times 6 \mathrm{~s}$, in case of muscle $20 \times 6 \mathrm{~s})$. After centrifugation $\left(40000 \mathrm{~g} ; 4^{\circ} \mathrm{C}\right.$, $20 \mathrm{~min}$ ), the supernatant as well as the washed (sodium phosphate buffer, see above) and resuspended sediment were assayed for PK activity. Blood $(\sim 750 \mathrm{ml})$ was immediately mixed with $50 \mathrm{ml}$ sodium phosphate buffer ( $5 \mathrm{mmol} / \mathrm{l} ; 154 \mathrm{mmol} / \mathrm{l} \mathrm{NaCl}, 64.5 \mathrm{mmol} / \mathrm{l}$ EDTA; $\mathrm{pH}$ 8.0) to prevent agglutination. Erythrocytes were collected by centrifugation, first at $600 \mathrm{~g}\left(7^{\circ} \mathrm{C}\right.$, $10 \mathrm{~min})$, after which the sediment was washed with sodium phosphate buffer $(5 \mathrm{mmol} / \mathrm{l} ; 154 \mathrm{mmol} / \mathrm{l} \mathrm{NaCl}$, $4 \mathrm{mmol} / \mathrm{l} \mathrm{EDTA}$; $\mathrm{pH}$ 8.0) and again centrifuged at $750 \mathrm{~g}$ $\left(7^{\circ} \mathrm{C}, 10 \mathrm{~min}\right)$. The collected cells were homogenized in 2.5 volumes $(\mathrm{v} / \mathrm{w})$ of sodium phosphate buffer $(5 \mathrm{mmol} / \mathrm{l}$; $1 \mathrm{mmol} / \mathrm{I} \mathrm{EDTA}, 1 \mathrm{mmol} / \mathrm{I} \mathrm{DTT} ; \mathrm{pH} 7.3$ ) by sonication $(6 \times 6 \mathrm{~s})$ and centrifuged $\left(40000 \mathrm{~g}, 4{ }^{\circ} \mathrm{C}, 20 \mathrm{~min}\right)$. Both supernatant and resuspended sediment were assayed for PK activity. For Western blot analysis, PK extracted from erythrocytes was concentrated by adding ammonium sulphate $\left(0.26 \mathrm{~g} / \mathrm{ml} ; \quad 0^{\circ} \mathrm{C}\right)$, centrifugation of the precipitated PK $\left(30000 \mathrm{~g}, 4^{\circ} \mathrm{C} ; 15 \mathrm{~min}\right)$ and then dissolved in $\mathrm{H}_{2} \mathrm{O}$.

\section{Electrophoresis and immunoblotting}

SDS-PAGE was performed according to Laemmli (1970) in a PHERO-minivert electrophoresis chamber (BiotecFischer $\mathrm{GmbH}, 35447$ Reiskirchen, Germany). Proteins were precipitated by mixing the sample with $10 \%(\mathrm{v} / \mathrm{v})$ of each $0.15 \%(\mathrm{w} / \mathrm{v})$ sodium deoxycholic acid and $72 \%$ $(\mathrm{w} / \mathrm{v})$ trichloroacetic acid. The samples were centrifuged at $10000 \mathrm{~g}$ for $10 \mathrm{~min}$ and the sediments were dissolved in Roti-Load 1 (diluted fourfold with $0.5 \mathrm{~mol} / \mathrm{l}$ Tris/ $\mathrm{HCl}$; $\mathrm{pH}$ 6.8) and incubated in closed tubes at $95^{\circ} \mathrm{C}$ for $6 \mathrm{~min}$. Proteins were separated in SDS gels consisting of $4 \%$ stacking gel and $10 \%$ running gel at $4{ }^{\circ} \mathrm{C}$ and $70 \mathrm{~V}$ (stacking gel) and at $130 \mathrm{~V}$ (running gel). Proteins were then stained with Coomassie blue or transferred to a nitrocellulose membrane by Western blotting using a Trans-Blot Semi-Dry (Bio-Rad Laboratories; $15 \mathrm{~V}$, $\left.\leq 5.5 \mathrm{~mA} / \mathrm{cm}^{2}, 20 \mathrm{~min}\right)$. LMW standard proteins for the determination of the relative molecular mass $\left(\mathcal{M}_{\mathrm{r}}\right)$ were phosphorylase, $97 \times 10^{3}$; albumin, $66 \times 10^{3}$; ovalbumin, $45 \times 10^{3}$; carbonic anhydrase, $30 \times 10^{3}$ and trypsin inhibitor $20.1 \times 10^{3}$.

Before the immunochemical test, protein transfer from the SDS gel to the membrane was assessed by reversible protein staining with Ponceau S $(0.2 \%(\mathrm{w} / \mathrm{v})$ in $3 \%(\mathrm{v} / \mathrm{v})$ acetic acid) and compared with the corresponding SDS gel. After washing the membrane four times with PBS $\left(139 \mathrm{mmol} / \mathrm{l} \mathrm{NaCl}, 12 \mathrm{mmol} / \mathrm{l} \mathrm{Na}_{2} \mathrm{HPO}_{4}, 3.6 \mathrm{mmol} / \mathrm{l}\right.$ $\mathrm{KH}_{2} \mathrm{PO}_{4} ; \mathrm{pH}$ 7.2), non-specific protein-binding sites were blocked with Roti-Block (diluted 1:10 with $\mathrm{H}_{2} \mathrm{O}$ ) at room temperature for $1 \mathrm{~h}$. The membrane was washed again four times in PBS and was then incubated overnight at room temperature with the primary antibody 
(goat anti-PK-M1 1:12 500 or rabbit anti-PK-S 1:500) in Roti-Block (1:10 diluted with $\mathrm{H}_{2} \mathrm{O}$ ) which was further diluted in the ratio of 1:3 with PBS. The membrane was then washed with PBS and incubated with the appropriate peroxidase-conjugated secondary antibody (antigoat IgG or anti-rabbit IgG (each 1:10 000 diluted in the same solution as the primary antibody)) for $1 \mathrm{~h}$ at room temperature, and washed again four times in PBS. The immune complexes were visualized by incubation with $3,3^{\prime}$-diaminobenzidine for 1-3 min. The incubation was stopped by washing the membrane with PBS.

\section{Sequencing of the N-terminus of purified boar sperm PK-S}

For partial sequencing of the structure-bound PK-S from boar spermatozoa, the purified enzyme was run on SDSPAGE (10\% gel, $0.75 \mathrm{~mm}$ thick) and transferred by Western blotting (semi-dry phase) to a PVDF-membrane. Proteins on the membrane were stained with Coomassie blue. The PK band at $64.5 \times 10^{3}$ was cut out for partial sequencing which was performed with an amino acid sequenator $\mathrm{ABI} 473 \mathrm{~A}$ at Würzburg University (TheodorBoveri-Institut, Physiologische Chemie II, Biozentrum, 97074 Würzburg, Germany).

\section{Production of antiserum against PK-S}

A polyclonal antiserum against boar sperm PK-S was produced by CovalAb (69007 Lyon, France). Before immunization the pre-immune sera of two rabbits were tested for unspecific immune reactions. An appropriate rabbit (New Zealand White, Norm SPF (specific pathogen free)) was then immunized following a standardized protocol (CovalAb). Purified PK-S $(4 \times 100 \mu \mathrm{g})$ was injected on multiple spots on day 0 (dissolved in complete Freund's adjuvant) and, for the booster injections, on days 21, 42 and 63 (in incomplete Freund's adjuvant). Terminal blood collection was on day 88.

\section{Purification of antibodies}

From the above antiserum, antibodies (anti-PK-S) were immunopurified using a peptide-coupled sepharose column (peptide synthesis and peptide immobilization on sepharose beads were also performed by CovalAb). To verify the specificity of the partial $\mathrm{N}$-terminal amino acid sequence of PK-S, protein databases (Swiss-Prot and TrEMBL) were searched. A peptide $\left(\mathrm{NH}_{2}\right.$-TSEAMPKAHMDAG-COOH) corresponding to the N-terminus of purified PK-S (see Fig. 3) was synthesized by CovalAb and coupled to sepharose in order to purify antibodies against this peptide by immunoaffinity chromatography of the final antiserum generated against PK-S.
The antiserum $(10 \mathrm{ml})$ was diluted in the ratio of $1: 1$ with PBS and mixed with the peptide-sepharose $(1 \mathrm{ml}$ in $5 \mathrm{ml}$ PBS containing $0.02 \%$ (w/v) sodium azide). The sepharose-serum-suspension was carefully shaken at $37{ }^{\circ} \mathrm{C}$ for $1 \mathrm{~h}$ and then incubated overnight at $4{ }^{\circ} \mathrm{C}$. The suspension was filled in a column, washed with $15 \mathrm{ml}$ PBS containing $0.1 \%(\mathrm{v} / \mathrm{v})$ Tween 20 and then with $30 \mathrm{ml}$ PBS, while release of protein was followed at $280 \mathrm{~nm}$. Antibodies were eluted by stepwise increasing the percentage $(10,20,30,40,60,80$ and $100 \%(\mathrm{v} / \mathrm{v}))$ of a glycin solution $(100 \mathrm{mmol} / \mathrm{l} ; \mathrm{pH}$ 2) in PBS. Fractions of $1 \mathrm{ml}$ each were collected in vessels containing $200 \mu \mathrm{l}$ Tris $(1 \mathrm{~mol} / \mathrm{l} ; \mathrm{pH} 8)$. Various fractions were used in immunoblotting to identify fractions that reacted specifically with PK-S.

\section{Immunofluorescence labelling of sperm PK}

Boar ejaculate was diluted in the ratio of 1:10 in BTS and $5 \mu \mathrm{l}$ of this sperm suspension were each smeared on a poly-L-lysine-precoated coverslip and left to dry. Sperm were then permeabilized with $0.1 \%(\mathrm{v} / \mathrm{v})$ Triton X-100 in PBS at room temperature for $5 \mathrm{~min}$. Thus, pretreated sperm were incubated, first with $0.01 \%(\mathrm{v} / \mathrm{v})$ Tween 20 in $\mathrm{PBS}$, then with $50 \mathrm{mmol} / \mathrm{I} \mathrm{NH} \mathrm{Nl}_{4} \mathrm{C}$ in $\mathrm{PBS}$ for 10 min each and washed again with PBS before being treated with blocking solution $(0.5 \%(\mathrm{w} / \mathrm{v})$ cold-water fish gelatine plus $0.1 \%(\mathrm{w} / \mathrm{v})$ ovalbumin in PBS) for $2 \mathrm{~h}$ at room temperature to occupy non-specific-binding sites. The spermatozoa were then incubated with primary antibodies (either goat anti-PK-M1 1:10 000 or rabbit anti-PK-S 1:5) in blocking solution overnight at $4{ }^{\circ} \mathrm{C}$. On the following day, after washing with PBS, sperm were incubated, for $2 \mathrm{~h}$ at room temperature in the dark, with secondary antibodies that were fluorescence-labelled (anti-goat IgG, Alexa Fluor 546 or anti-rabbit IgG, Alexa Fluor 568; dilution 1:400 in PBS). Finally sperm were washed in PBS and in bidistilled water and mounted in Mowiol 4.88. Fluorescence labelling was analysed with a DM RP microscope (Leica, 64625 Bensheim, Germany). Images were taken with a Hamamatsu ORCA ER CCD camera (Hamamatsu, 82211 Herrsching, Germany) and processed using Photoshop (Adobe Systems Inc., Version 7.0).

\section{Immunogold labelling}

Fresh boar sperm were fixed and embedded in LR White as previously described (Westhoff \& Kamp 1997). Ultrathin sections were collected on polyvinyl formal (Formvar)-coated nickel grids, etched for 2 min with saturated sodium periodate and further processed for immunogold labelling as described by Wolfrum \& Schmitt (2000). The antibodies were diluted as follows: goat anti-PK-M1 1:10 000; rabbit anti-PK-S 1:5; anti-goat 
$\lg 1: 15$ and anti-rabbit $\lg$ 1:28. Sections were counterstained for $10-20 \mathrm{~min}$ with $2 \%(\mathrm{w} / \mathrm{v})$ aqueous uranyl acetate and subsequently for 2 min with lead citrate according to Hanaichi et al. (1986). Immunogold labelling was analysed by electron microscope (FEI Tecnai 12 Biotwin; 5600 KA Eindhoven, The Netherlands).

As an additional control for antibody specificity, primary antibodies were pre-incubated with their respective antigens at $37^{\circ} \mathrm{C}$ under gentle agitation for $1 \mathrm{~h}$ and subsequently at $4{ }^{\circ} \mathrm{C}$ for $2 \mathrm{~h}$. The immune complexes were then sedimented $\left(10000 \mathrm{~g} ; 4{ }^{\circ} \mathrm{C}\right.$, $15 \mathrm{~min}$ ) and the supernatant was used as in immunogold labelling. One hundred micrograms of the spermspecific PK-peptide per $6 \mu \mathrm{l}$ immunopurified antibodies and $160 \mu \mathrm{g}$ rabbit muscle PK per microgram of antirabbit muscle PK were used for pre-absorption of primary antibodies.

In case of immunogold localization with anti-PK-S, the labelling density of the fibrous sheath was determined. The area of the fibrous sheath in an electron micrograph was calculated by pixel counting based on scale bars $\left(\mu \mathrm{m}^{2}\right.$ per pixel). All gold particles in this area of fibrous sheath were counted. Labelling density is the number of gold particles per micrometer square of fibrous sheath area and given as mean \pm s.D., based on counting four separate electron micrographs of slices treated with anti-PK-S (total fibrous sheath area $0.98 \mu \mathrm{m}^{2}$ ) as well as four controls treated with preincubated anti-PK-S (total fibrous sheath area $1.14 \mu \mathrm{m}^{2}$ ). Counting was done without knowing how the specimens had been treated. Statistical significance was analysed with a Student's $t$-test. Results were considered to be significant if $P<0.05$.

\section{Results}

\section{Extraction of PK from boar sperm}

When boar sperm were sonicated in sodium phosphate buffer (25 mmol/l; pH 7.3) and centrifuged (100000 g, $1 \mathrm{~h}$ ) more than $60 \%$ of the total PK activity, which was $0.41 \pm 0.14 \cup$ per $10^{8}$ spermatozoa (at $25^{\circ} \mathrm{C}, n=8$ ), was sedimented. This PK could not be washed out from the sediment by phosphate buffer, indicating that soluble and sedimented PKs are not in equilibrium. For better differentiation we designate the tightly bound sperm PK as PK-S. Triton X-100, which solubilized sperm hexokinase (Travis et al. 1998), did not solubilize PK-S in the range of $0.5-3 \%(\mathrm{v} / \mathrm{v}$ in $25 \mathrm{mmol} / \mathrm{l} \mathrm{NaP}, 1 \mathrm{mmol} / \mathrm{I}$ EDTA and $1 \mathrm{mmol} / \mathrm{I} \mathrm{DTT}$; $\mathrm{pH} 7.3)$, but the bound PK-S was considerably activated by Triton X-100 (>50\%), whereas the activity of soluble PK was not affected. A brief tryptic digestion, however, as had been used for solubilizing GAPDH (Westhoff \& Kamp 1997), did release catalytically active PK-S from boar sperm structures. Trypsin (at $3 \mathrm{mg} / \mathrm{g}$ sperm wet weight) solubilized about $80 \%$ of PK-S in $5 \mathrm{~min}$ at room temperature with no loss of catalytic activity. Consequently, trypsin treatment was efficient for purification of PK-S (Table 1). However, GAPDH was also prominent in extracts after trypsin treatment of sperm sediment and had to be separated from PK-S by chromatography.

\section{Purification of boar sperm PK-S}

The trypsin extract containing solubilized PK-S was applied to a column of Fractogel EMD $\mathrm{SO}_{3}^{-}(\mathrm{S})$ and eluted with $38 \mathrm{mmol} / \mathrm{l}$ phosphate buffer. Although this ion exchange chromatography increased sevenfold the specific activity of PK-S (Table 1), it was not efficient in separating PK-S from GAPDH (Fig. 1A). Separation was achieved by hydrophobic interaction chromatography on Fractogel EMD Propyl (S) to which both enzymes were bound at $30 \%$ ammonium sulphate (Fig. 1B). In presence of $20.5 \%$ ammonium sulphate PK-S remained bound to the column, whereas most GAPDH was released. PK-S was eluted at $14 \%$ ammonium sulphate. The combined PK-S fractions had a specific activity of $116.7 \mathrm{U} / \mathrm{mg}$ protein. Thus, the purification factor for PK was almost 1000, but the preparation still contained traces of GAPDH $\left(M_{\mathrm{r}} 42 \times 10^{3}\right)$ in SDS-PAGE (Table 1 and Fig. $2 \mathrm{~A}$ ). The prominent protein at $64.5 \times 10^{3}$ was identified as PK in a Western blot using anti-rabbit

Table 1 Purification of boar sperm PK-S.

\begin{tabular}{|c|c|c|c|c|c|c|c|}
\hline & \multirow[b]{2}{*}{$\underset{(\mathrm{ml})}{\text { Volume }}$} & \multirow[b]{2}{*}{$\begin{array}{l}\text { Protein } \\
(\mathrm{mg})\end{array}$} & \multicolumn{3}{|c|}{ Pyruvate kinase activity $(U)$} & \multirow[b]{2}{*}{$\begin{array}{l}\text { Purification } \\
\text { factor }\end{array}$} & \multirow[b]{2}{*}{$\begin{array}{l}\text { PK:GAPDH } \\
\text { ratio }\end{array}$} \\
\hline & & & Total & $\begin{array}{l}\text { Per milligram } \\
\text { of protein }\end{array}$ & $\begin{array}{l}\text { Yield (\%) of } \\
\text { PK-S }\end{array}$ & & \\
\hline Sperm homogenate ${ }^{a}$ & 720 & 9415 & 1085 & 0.12 & & & \\
\hline Supernatant after trypsin incubation & 390 & 243 & 720 & 2.96 & 100 & 24.7 & \\
\hline $\begin{array}{l}\text { PK fractions after ion exchange } \\
\text { chromatography }\end{array}$ & 198 & 22.7 & 461 & 20.3 & 64 & 169.2 & 0.2 \\
\hline $\begin{array}{l}\text { PK fractions after hydrophobic } \\
\text { interaction chromatography }\end{array}$ & 12 & 2.1 & 245 & 116.7 & 34 & 972.5 & 32.1 \\
\hline
\end{tabular}

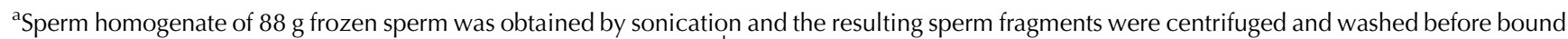
PK (PK-S) was solubilized by trypsin (see Materials and Methods). ${ }^{\text {b}}$ After centrifugation solubilized PK-S was subjected to ion exchange chromatography (see Fig. 1A) and hydrophobic interaction chromatography (see Fig. 1B). 

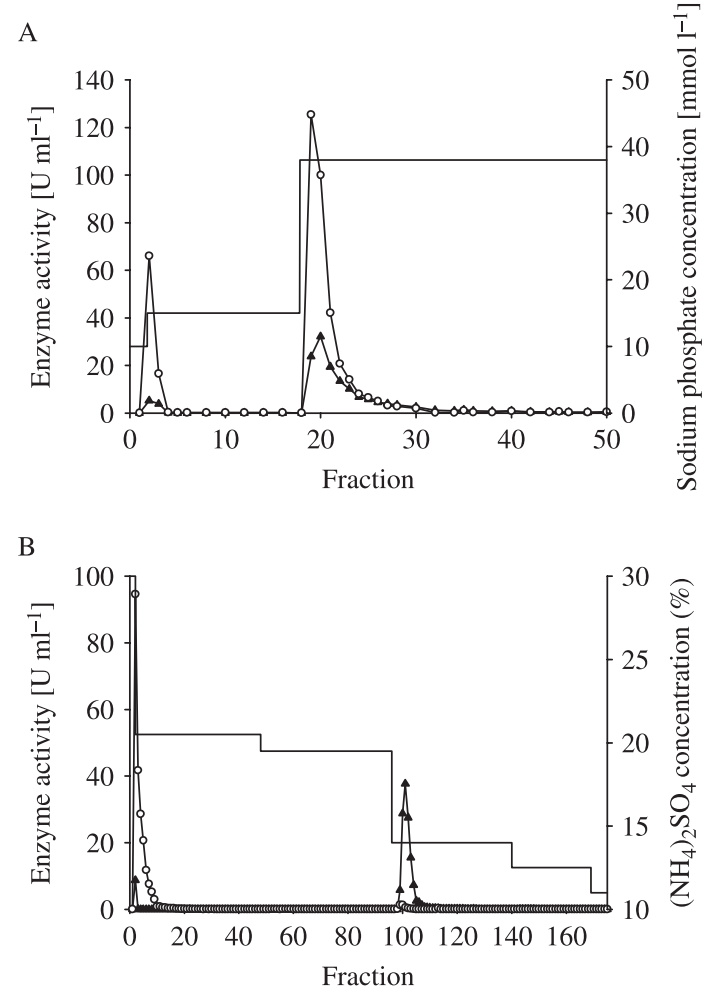

Figure 1 Elution profiles of PK-S and GAPDH activities extracted from boar spermatozoa by trypsin treatment and subjected to an ion exchange (A) and subsequently to a hydrophobic interaction chromatography (B). (A) Extract of trypsin-treated sperm fragments containing solubilized PK-S and GAPDH were chromatographed on Fractogel $\mathrm{EMD} \mathrm{SO}_{3}^{-}$(S). Both enzymes were eluted by stepwise increasing the sodium phosphate concentration. Most PK-S (- - -) but also much GAPDH (-O-) activity was eluted with $38 \mathrm{mmol} / \mathrm{l}$ sodium phosphate. (B) The fractions of PK-S and GAPDH eluted at $38 \mathrm{mmo} / / \mathrm{l}$ sodium phosphate from chromatography $(\mathrm{A})$ were pooled and adjusted to $30 \%\left(\mathrm{NH}_{4}\right)_{2} \mathrm{SO}_{4}$ and $\mathrm{pH} 7.3$. Applied on Fractogel EMD Propyl (S) nearly all GAPDH (-O-) was eluted by reducing $\left(\mathrm{NH}_{4}\right)_{2} \mathrm{SO}_{4}$ to $20.5 \%$, whereas most PK-S activity (- $\mathbf{\Delta - )}$ appeared in a narrow peak at $14 \%\left(\mathrm{NH}_{4}\right)_{2} \mathrm{SO}_{4}$.

muscle PK (anti-PK-M1; Fig. 2B). This PK-S preparation was used for producing an antiserum in rabbit.

\section{Kinetics of somatic and sperm PKs}

PK isozymes from mammalian tissues differ in their kinetic properties. Muscle (PK-M1) is characterized by high affinity for the substrate PEP. It lacks activation by fructose 1,6 -bisphosphate $\left(\mathrm{F}^{1}, 6 \mathrm{P}_{2}\right)$ and inhibition by $\mathrm{L}$-alanine, two properties that are typical for the liver isozyme (PK-L) as well as for the isozymes PK-M2 and PK-R (see Table 2). PK-S bound to boar sperm structures showed kinetic behaviour similar to that of PK-M1. Solubilization of PK-S by trypsin did not significantly change the kinetics suggesting that binding to cell structure did not influence the catalytic properties of boar sperm PK-S. Soluble sperm PK also showed similar kinetics as PK-S and PK-M1 (not shown). In control

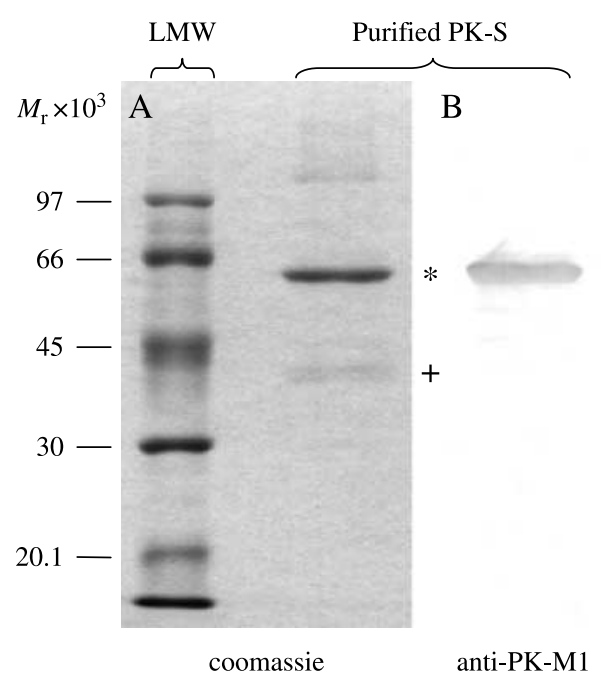

Figure 2 SDS-PAGE (A) and Western blot (B) of PK-S purified from boar spermatozoa. (A) The purified boar sperm PK-S gave rise to a prominent protein band at $64.5 \times 10^{3}\left(^{*}\right)$. LMW standard proteins (lane 1) are listed in Materials and Methods. The minor band at $M_{\mathrm{r}} 42 \times 10^{3}\left(^{+}\right)$is probably due to GAPDH (see text). (B) Boar sperm PK-S was recognized by anti-rabbit PK-M1. This PK-S preparation was used for antibody production. PK-S was also cut out from a blot and used for $\mathrm{N}$-terminal sequencing.

experiments, we extracted PK-L from mouse liver and showed it to be activated by $\mathrm{F} 1,6 \mathrm{P}_{2}$ and inhibited by L-alanine (data not shown), properties that we did not observe with rabbit muscle and boar sperm PKs assayed under identical conditions.

\section{Sequencing of boar sperm PK-S}

The purified boar sperm PK-S was run on SDS-PAGE (Fig. 2) and blotted onto PVDF, and the prominent PK band was cut out for sequencing the $\mathrm{N}$-terminus. Eighteen of the first 19 amino acids were identified: $\mathrm{NH}_{2}$-TSEAMPKAHMDAGXAFIQT-COOH ( $\mathrm{X}=$ unidentified). Comparison with sequences from protein databases (Swiss-Prot, TrEMBL) revealed that $7-11$ of 14 amino acids were identical with the N-termini of PK-M1 or PK-M2 if the first five amino acids of the solubilized PK-S were neglected (Fig. 3). When compared with the corresponding sequences of PK-L or PK-R, only 4 out of 14 amino acids were identical. The sequences of PK-M1 which were derived from protein sequencing indicate that PK-M1 lacks the five N-terminal amino acids that were found in the solubilized PK-S. Consequently, the designation of the structurally bound boar sperm PK as PK-S is justified.

Most PK sequences in protein databases have been derived from the analysis of cDNA. One of the PK-M2 (Homo) thus deduced would have an $\mathrm{N}$-terminal extension including the sequence $\mathrm{NH}_{2}$-TSAA-COOH where PK-S has $\mathrm{NH}_{2}$-TSEA- $\mathrm{COOH}$. Another sequence, most probably encoding a $\mathrm{PK}$, derived from a cDNA library of bovine ileum, showed the sequence $\mathrm{NH}_{2}$ TSEA-COOH in an N-terminal extension at the same 
Table 2 Comparison of boar sperm PK-S (structure bound and solubilized by trypsin) and somatic pyruvate kinases with respect to kinetics and molecular mass.

\begin{tabular}{|c|c|c|c|c|c|c|}
\hline \multirow[b]{2}{*}{ Isozyme } & \multicolumn{2}{|c|}{ PK-S } & \multirow[b]{2}{*}{ PK-M1 ${ }^{\mathrm{a}}$} & \multirow[b]{2}{*}{ PK-L ${ }^{\mathrm{a}}$} & \multirow[b]{2}{*}{ PK-R ${ }^{a}$} & \multirow[b]{2}{*}{ PK-M2 $(-A)^{a}$} \\
\hline & Bound & Solubilized & & & & \\
\hline Source & & perm & $\begin{array}{l}\text { Skeletal muscle, } \\
\text { cardiac muscle, } \\
\text { and brain }\end{array}$ & $\begin{array}{l}\text { Liver (parenchymal } \\
\text { cells) }\end{array}$ & Erythrocytes & $\begin{array}{l}\text { Kidney, lung, leukocytes, } \\
\text { adipose tissue, liver (stromal } \\
\text { cells), and fetal tissues }\end{array}$ \\
\hline $\begin{array}{l}\text { Relative molecular } \\
\text { mass/molecular } \\
\text { weight per subunit } \\
\left(\times 10^{-3}\right)\end{array}$ & & $64 \pm 1$ & $52.5-62.5$ & $50-60$ & $50-60$ & $47.5-62.5$ \\
\hline$K_{\mathrm{m}}(\mathrm{PEP} ; \mathrm{mM})$ & $0.02-0.05$ & $0.02-0.03$ & $0.04-0.09$ & $0.3-1.0$ & $0.5-0.6$ & $0.2-0.4$ \\
\hline$K_{\mathrm{m}}(\mathrm{ADP} ; \mathrm{mM})$ & $0.52-0.56$ & 0.46 & $0.3-0.4$ & $0.1-0.4$ & $0.4-0.6$ & $0.2-0.4$ \\
\hline $\begin{array}{l}\text { Activation by } \\
\mathrm{F} 1,6 \mathrm{P}_{2}\end{array}$ & $\mathrm{No}^{\mathrm{b}}$ & $\mathrm{No}^{\mathrm{b}}$ & $\mathrm{No}^{\mathrm{b}}$ & Yes $^{b}$ & Yes & Yes \\
\hline $\begin{array}{l}\text { Inhibition by } \\
\text { L-alanine }\end{array}$ & $\mathrm{No}^{\mathrm{b}}$ & $\mathrm{No}^{\mathrm{b}}$ & $\mathrm{No}^{\mathrm{b}}$ & $Y_{e s}{ }^{b}$ & Yes & Yes \\
\hline
\end{tabular}

${ }^{\mathrm{a} D a t a}$ from Hall \& Cottam (1978). ${ }^{\mathrm{b}}$ The effect of fructose 1,6-bisphosphate ( $\left.\mathrm{F} 1,6 \mathrm{P}_{2}, 0.2 \mathrm{mmol} / \mathrm{l}\right)$ was assayed at $0.1 \mathrm{mmol} / \mathrm{l} \mathrm{PEP}$, phosphoenolpyruvate, the effect of L-alanine $(1 \mathrm{mmol} / \mathrm{l})$ at $1 \mathrm{mmol} / \mathrm{I} \mathrm{PEP.} \mathrm{ADP} \mathrm{was} \mathrm{given} \mathrm{at} 1 \mathrm{mmol} / \mathrm{l}$ in all assays.

position as in PK-S (see Fig. 3). Interestingly, in the bovine ileum PK this sequence is preceded by a lysine thus defining a trypsin cleavage site. A lysine at the same position in boar sperm PK-S would explain the tryptic cleavage of this enzyme from boar sperm structures and suggest that the $\mathrm{N}$-terminus of native PK-S is longer than that obtained by tryptic cleavage.

\section{Specificity of anti-PK-S}

The $\mathrm{N}$-terminal peptide $\left(\mathrm{NH}_{2}\right.$-TSEAMPKAHMDAG$\mathrm{COOH}$ ) of purified boar sperm PK-S was synthesized and immobilized on sepharose for purification of PK-S antibodies from the rabbit antiserum as described in Materials and Methods. The purified anti-PK-S was tested for specificity in Western blots after SDS-PAGE (Figs 4-6). One fraction of anti-PK-S eluted from the peptide-sepharose column specifically labelled PK-S. In contrast, rabbit muscle as well as boar sperm GAPDH were not or only faintly labelled even if the protein concentrations of these enzymes were high (Fig. 4). PK-S was detected in extracts of trypsin-treated boar sperm fragments (Fig. 4, TSP) and in an enriched PK-S preparation which was still contaminated with GAPDH (Fig. 4, PK/GAPDH). Boar sperm extract not treated with trypsin was not labelled although it contained soluble PK (Fig. 4, SP). Even when enriched by ion exchange and hydrophobic interaction chromatography soluble sperm PK (sPK) was not detected by anti-PK-S (Fig. 5). Hence, the anti-PK-S discriminates between PK-S and soluble PK from boar spermatozoa and can be regarded as specific for PK-S, which is a prerequisite for identification and localization of PK-S by fluorescence or immunogold labelling. In contrast to anti-PK-S, anti-rabbit PK-M1 detected both the soluble boar sperm PK and PK-S (data not shown). Specificity of anti-PK-S for sperm PK-S was also indicated by the observation that it did not recognize PKs from boar organs and cells such as muscle, liver, kidney or erythrocytes, whereas antiPK-M1 did (Fig. 6). Unlike sperm PK-S, all PKs of these somatic cells did not require tryptic digestion for solubilization. More than $90 \%$ of their activities were extracted in sodium phosphate buffer.

\section{Localization of PK-S in boar sperm}

Ejaculated boar spermatozoa were permeabilized (with Triton X-100) on poly-L-lysine-precoated coverslips and incubated with anti-PK-S (Fig. 7A and C) and anti-PK-M1 (Fig. 7B and D) for immunofluorescence microscopy. Figure 7A and $B$ shows differential interference contrast (DIC) images merged with antibody fluorescence, whereas in Fig. $7 \mathrm{C}$ and $\mathrm{D}$ only the red fluorescence is seen. Incubating sperm with anti-PK-S resulted in compartmentation of the fluorescence label, which is conspicuous in the principal piece of the flagellum and in the acrosomal area of the sperm head (Fig. 7A and C) but hardly noticeable in the midpiece. A significant fluorescence was also detected at the head-midpiece junction. Under otherwise identical conditions, controls without the primary antibody showed no fluorescence (data not shown).

With anti-PK-M1, the whole flagellum and the acrosomal area were stained (Fig. 7B and D). Controls without the primary antibody showed only unspecific fluorescence at the acrosome and midpiece which was much weaker than the reaction to anti-PK-M1 (data not shown).

In summary, labelling of sperm with both antibody preparations indicates that PK-S is mainly confined to the 


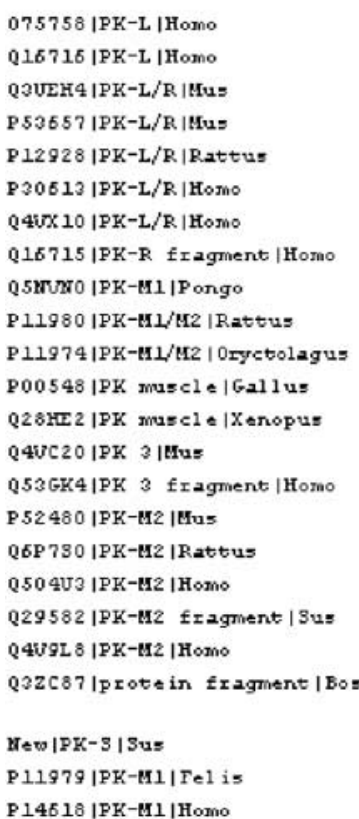

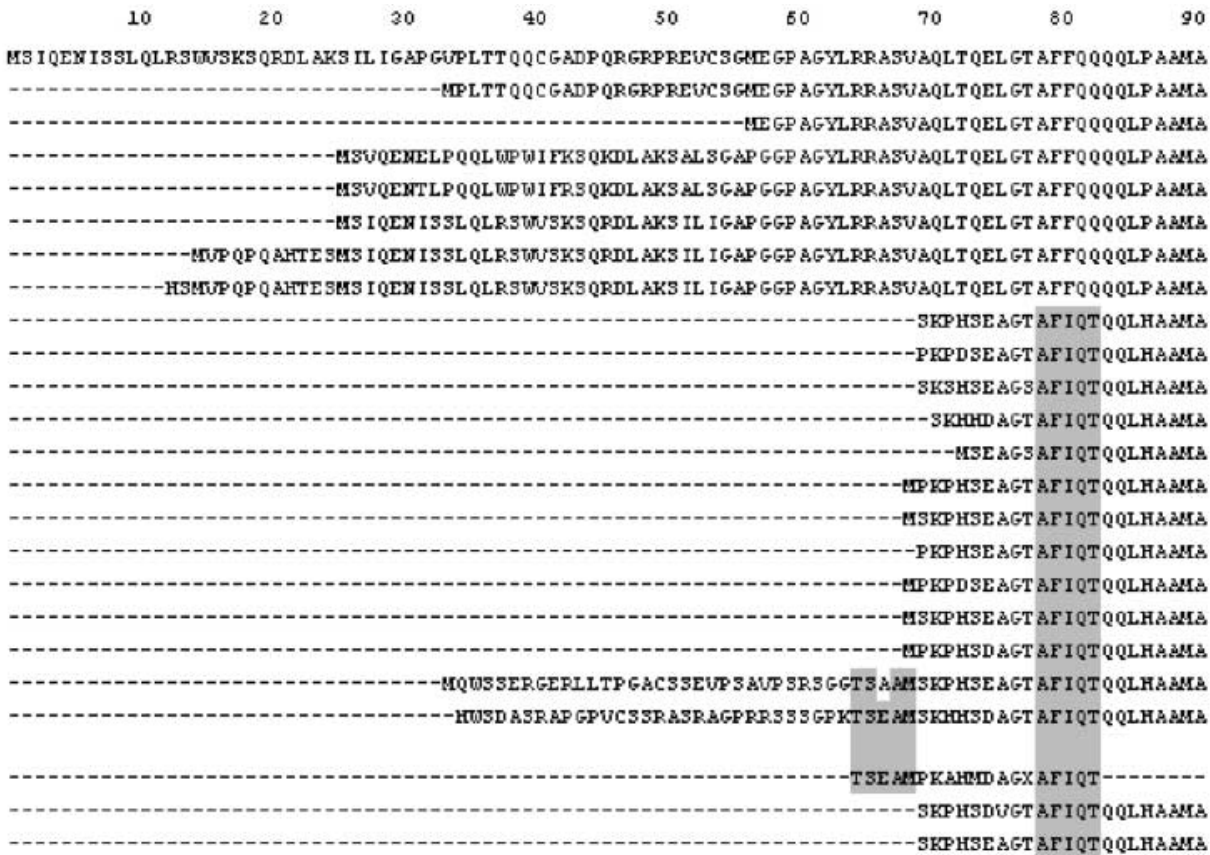

Figure 3 Comparison of the N-terminal amino acid sequences of the tryptically solubilized sperm PK-S and of somatic pyruvate kinases of various sources. Sequences of somatic pyruvate kinases obtained from Swiss-Prot and TrEMBL are compared with the N-terminal sequence of purified PK-S (New |PK-S| Sus; $X=$ unidentified amino acid). The 21 sequences of somatic pyruvate kinases that are listed above PK-S were derived from cDNA and/or genomic DNA analyses, the sequence of $\mathrm{PK}-\mathrm{S}$ and the two last sequences from protein sequencing. Except for the first five amino acids $\left(\mathrm{NH}_{2}-\right.$ TSEAM-COOH), the sperm PK-S sequence shows a high degree of similarity to the respective sequences of PK-M1 and PK-M2 (50-78\%). The sequence $\mathrm{NH}_{2}$-AFIQT-COOH is present in all PK-Ms and also in PK-S (under laid), but not in PK-L and PK-R. Two PK-M sequences (Homo and Bos) deduced from cDNAs show identical or nearly the same amino acids (under laid) at corresponding positions as the N-terminal extension of PK-S.

principal piece of the flagellum and to the acrosomal area, whereas labelling of the midpiece with anti-PK-M1 only, suggests that soluble PK is present in this area.

For ultrastructural localization of PK, immunogold electron microscopy was used (Figs 8 and 9). With antiPK-M1 relatively few gold particles were found in the midpiece, but the principal piece was markedly labelled, mainly at the fibrous sheath (Fig. 8A and B). In sperm head, the acrosomal area was labelled, but also the nucleus and the postacrosomal substance showed some gold particles (Fig. 8D and E). Controls with anti-PK-M1 pre-incubated with rabbit muscle PK were virtually free from label (Fig. 8C and F).

With anti-PK-S, labelling at the fibrous sheath (Fig. 9A and B) occurred to a lesser extent than with anti-PK-M1. Yet anti-PK-S significantly labelled the fibrous sheath when compared with controls with pre-incubated antibodies (Fig. 9C). Labelling density was $66 \pm 27$ vs $26 \pm 5$ in controls (see Materials and Methods). The acrosomal area was conspicuously labelled (Fig. 9D, E and $\mathrm{H}$ ), while the postacrosomal substance was virtually free from labels (Fig. 9D and G). Controls with anti-PK-S

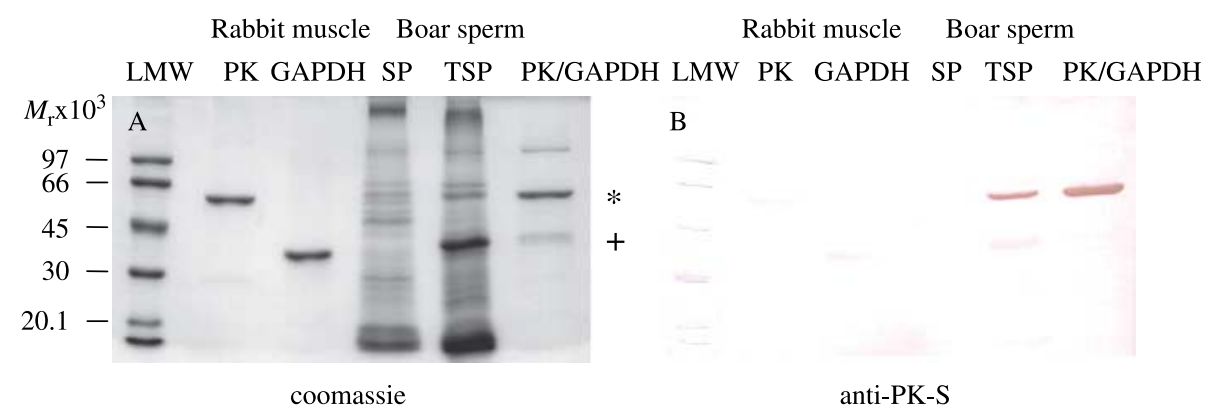

Figure 4 Specificity of antibodies purified by immune affinity from a serum raised against boar PK-S. (A) Purified rabbit muscle PK and GAPDH as well as proteins extracted from boar sperm without (SP, soluble proteins) and with trypsin treatment (TSP, tryptically solubilized proteins) as well as a sample enriched in PK-S containing traces of GAPDH (PK/GAPDH) were run by SDS-PAGE. LMW standard proteins are listed in Materials and Methods. (B) The Western blot of (A) indicates that PK-S $\left(^{*}\right)$ in sperm extract after trypsin treatment and in the PK/GAPDH preparation is recognized by anti-PK-S. Although their protein concentrations were high, muscle PK and GAPDH as well as boar sperm GAPDH $\left({ }^{+}\right)$were hardly stained. Other proteins extracted from boar spermatozoa were not detected. Standard proteins were faintly marked with a pencil. 


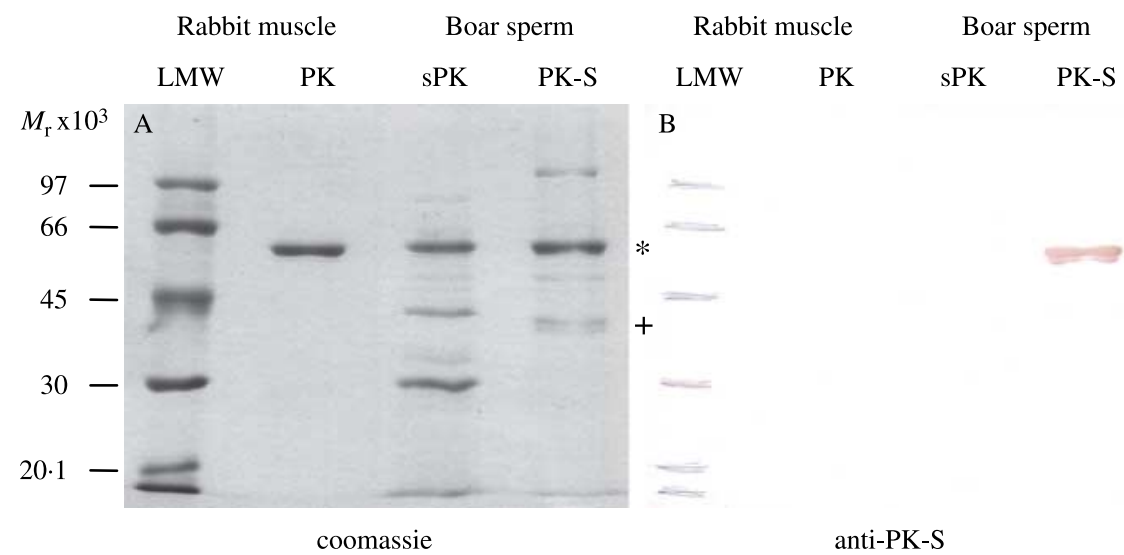

Figure 5 The soluble PK (sPK) from boar sperm is not recognized by anti-boar PK-S. To test whether or not sPK was labelled by anti-PK-S, sPK was partly purified by a procedure similar to that shown in Fig. 1 for PK-S and run on a gel (A) together with rabbit muscle PK and boar sperm PK-S. (A) sPK and PK-S produced significant protein bands $\left({ }^{*}\right)$ and weak GAPDH band $\left({ }^{+}\right)$. LMW standard proteins are listed in Materials and Methods. (B) The western blot of (A) shows that anti-PK-S did recognize PK-S but neither the soluble sperm PK (sPK) nor the rabbit muscle PK. Hence, anti-PK-S is regarded specific for sperm PK-S. LMW standard proteins were marked with a pencil after reversible protein staining.

that had been pre-incubated with the PK-S-specific peptide showed only sporadic labels (Fig. 9F).

\section{Discussion}

\section{Two PKs in boar spermatozoa}

Novel forms of glycolytic enzymes in sperm were identified from nucleotide sequences of GAPDH (GAPDH-S; Welch et al. 1992, 2000, 2006) and HK (HK1-S; Mori et al. 1993, Travis et al. 1998). The corresponding amino acid sequences of both enzymes have unusual N-termini. While GAPDH-S is $\mathrm{N}$-terminally extended, HK1-S lacks the N-terminal porin-binding domain of HK1, which is replaced by a spermatogenic cell-specific region. During spermatogenesis both proteins appear first in spermatids. The PK-S of boar spermatozoa is the third glycolytic enzyme containing an unusual N-terminus. PK-S is similar to the native muscle isozyme PK-M1, but like GAPDH-S N-terminally extended (see Fig. 3: P11979|PK-M1|Felis, Muirhead et al. 1986; P14618|PK-M1|Homo, Gevaert et al. 2003), so that its relative molecular mass slightly exceeds that of rabbit PK-M1.

Two genes, $P K M$ and $P K L$, are known for mammalian PK isozymes. PK-M1 and PK-M2 are encoded by the $P K M$ gene in rat and man and differ due to alternative splicing of the same primary transcript (Takenaka et al. 1989, 1991). In case of the $P K L$ gene, alternative tissuespecific promoters lead to the production of $P K-L$ and $P K-R$ transcripts in rat (Noguchi et al. 1987). The $\mathrm{N}$-termini of PK-L and PK-R are considerably extended when compared with PK-M1/M2 and might be responsible for differences in kinetic properties (cf. Muirhead et al. 1986). The sequenced part of the novel isoform PK-S is more similar (7-11 of 14 amino acids identical) to PK-M1 and PK-M2, than to PK-L and PK-R (4 out of 14 amino acids identical) if the first five amino acids of the $\mathrm{N}$-terminus of PK-S were neglected. Especially the highly conserved sequence $\mathrm{NH}_{2}$-AFIQT-COOH is present in PK-M1/M2 and in PK-S, but not in PK-L/R (see Fig. 3, positions 79-83). Therefore, we assume that PK-S is encoded by the $P K M$ gene and that the different $\mathrm{N}$-terminus arises from alternative initiation or posttranscriptional modification.

The $\mathrm{N}$-terminus of the native PK-M1 begins at position 70 (see Fig. 3) which is preceded by a methionine in the $\mathrm{N}$-terminal extension of PK-S ( $\mathrm{NH}_{2}$-TSEAM-COOH). This methionine is also present in some sequences deduced from cDNA/mRNA or genomic DNA for PK-M1 and PK-M2 (see Fig. 3). From human cDNA (source: chondrosarcoma lung metastasis), a sequence of mRNA for PK-M2 has been derived that contains an AUG start codon upstream of an extension sequence so that the deduced protein would have an $\mathrm{N}$-terminal extension with a methionine at position 35 and a sequence similar to PK-S at positions 65-69 (TrEMBL accession number Q4V9L8; Fig. 3). In addition a hypothetical protein from bovine ileum (TrEMBL accession number Q3ZC87) seems to be an $\mathrm{N}$-terminally extended PK-M1 or PK-M2 with the same

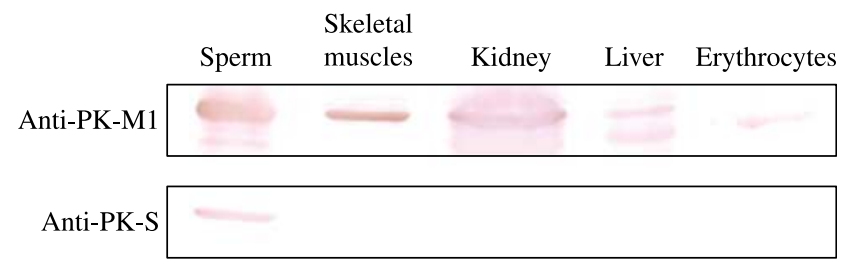

Figure 6 Western blots of extracts from boar organs and cells incubated with antibodies directed against PK-M1 and PK-S. Unlike sperm PK-S, pyruvate kinases were readily extracted from somatic organs and cells by homogenization in phosphate buffer (see Materials and Methods) and were recognized by anti-PK-M1 but not by anti-PK-S. Anti-PK-S stained only PK-S which is further evidence that PK-S is a sperm specific enzyme. 

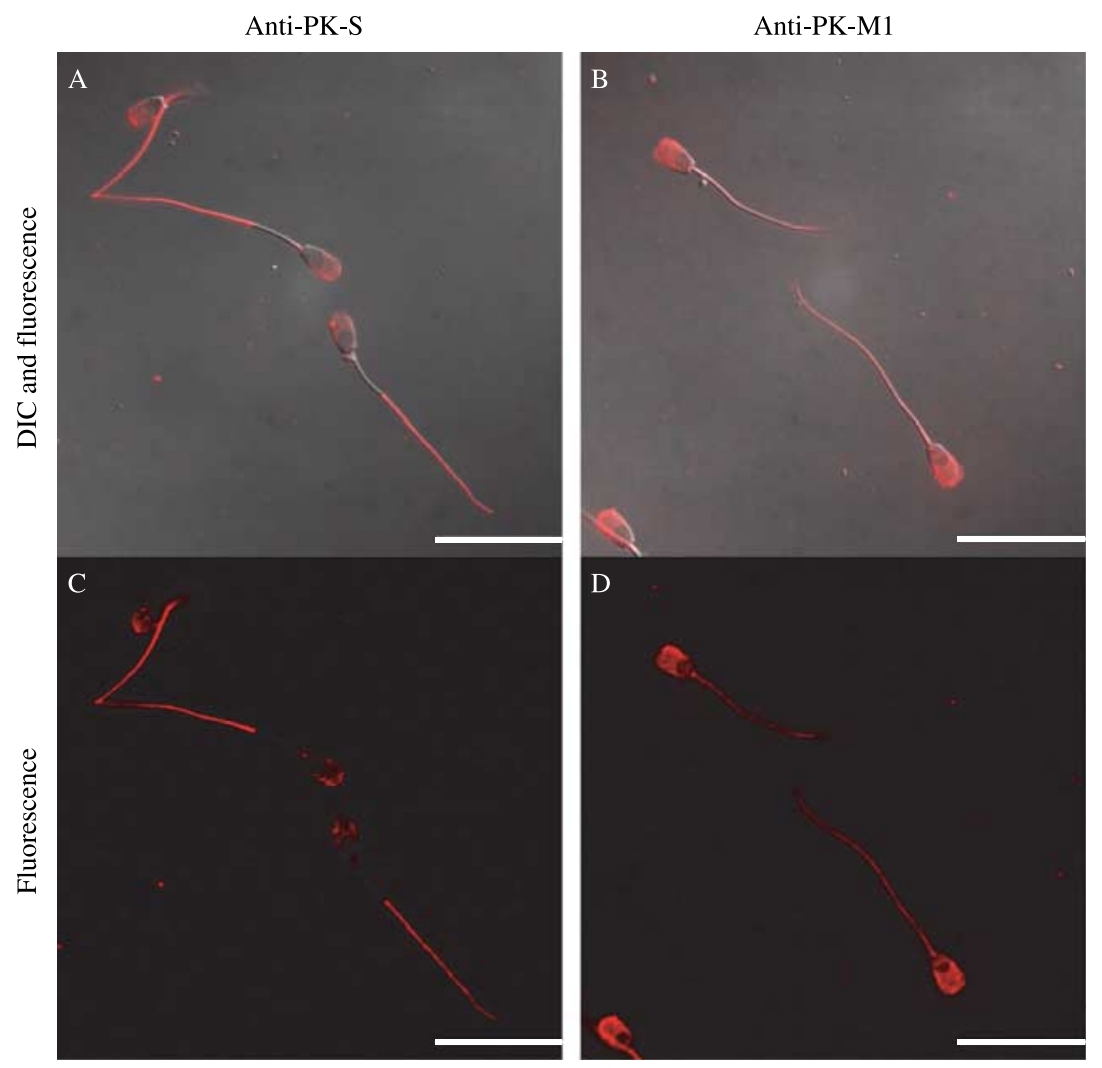

Figure 7 Localization of PK in boar spermatozoa by immunofluorescence microscopy. Immunofluorescence of boar sperm merged with differential interference contrast (DIC) images is shown in (A and $\mathrm{B})$, fluorescence only in (C and $\mathrm{D})$. Rabbit antiPK-S (A and C) and goat anti-PK-M1 (B and D) were used for labelling PK in boar spermatozoa. With anti-PK-S the principal piece of the flagellum and the acrosome as well as the head-midpiece junction are specifically labelled. In contrast to anti-PK-S, anti-PK-M1 labelled the midpiece as well. The control without anti-PK-M1 had a weak unspecific fluorescence at the acrosome and the midpiece (not shown). Scale bars $=16.5 \mu \mathrm{m}$.

amino acid sequence $\left(\mathrm{NH}_{2}\right.$-TSEA(M)-COOH) as PK-S. Nucleotide sequence databases (GenBank, EMBL, DDBJ and PDB) contain PKM mRNAs that have sequences preceding the $5^{\prime}$-site of the predicted start codon AUG that encode amino acids similar to those of the extension of PK-S (Fig. 10). This is a further indication that PK-S is encoded by the $P K M$ gene. Since $\mathrm{N}$-terminal sequences of native PK-M2 are not available it cannot be excluded that PK-M2 may show a similar extension as PK-S. Kinetic properties, however, indicate that PK-S resembles PK-M1 rather than PK-M2. Therefore, we assume that PK-S is an $\mathrm{N}$-terminally extended PK-M1.

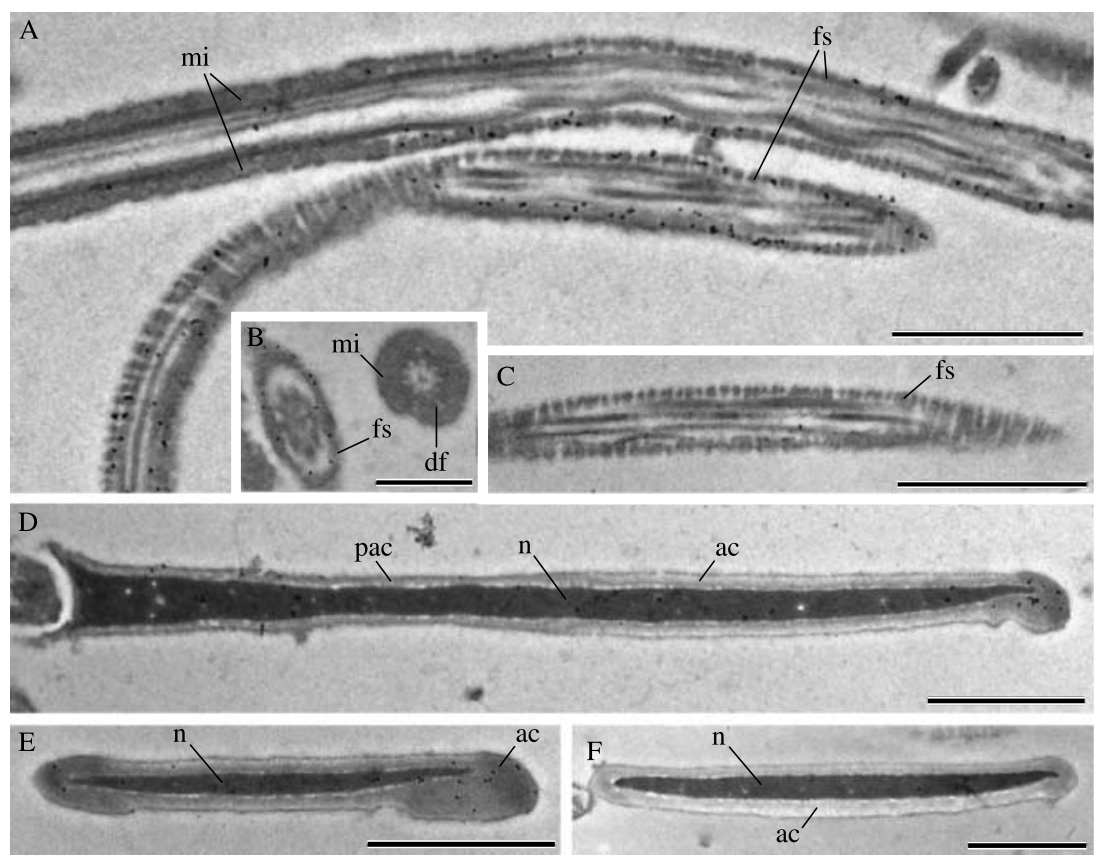

Figure 8 Ultrastructural localization of PK in boar sperm by immunogold electron microscopy using anti-PK-M1. Anti-PK-M1 significantly labelled the fibrous sheath, while only few gold particles were found on other structures of the flagellum (A and B). The area of the acrosome was also labelled ( $D$ and $E$ ). Few gold particles were found in the nucleus and the postacrosomal substance. When anti-PK-M1 was pre-incubated with rabbit muscle PK-M1, slices were not labelled (controls; $\mathrm{C}$ and F). Scale bars $=1 \mu \mathrm{m}$, in $B=0.5 \mu \mathrm{m}$. ac, acrosome; $\mathrm{df}$, dense fibres; fs, fibrous sheath; mi, mitochondria; $\mathrm{n}$, nucleus; pac, postacrosomal substance. 

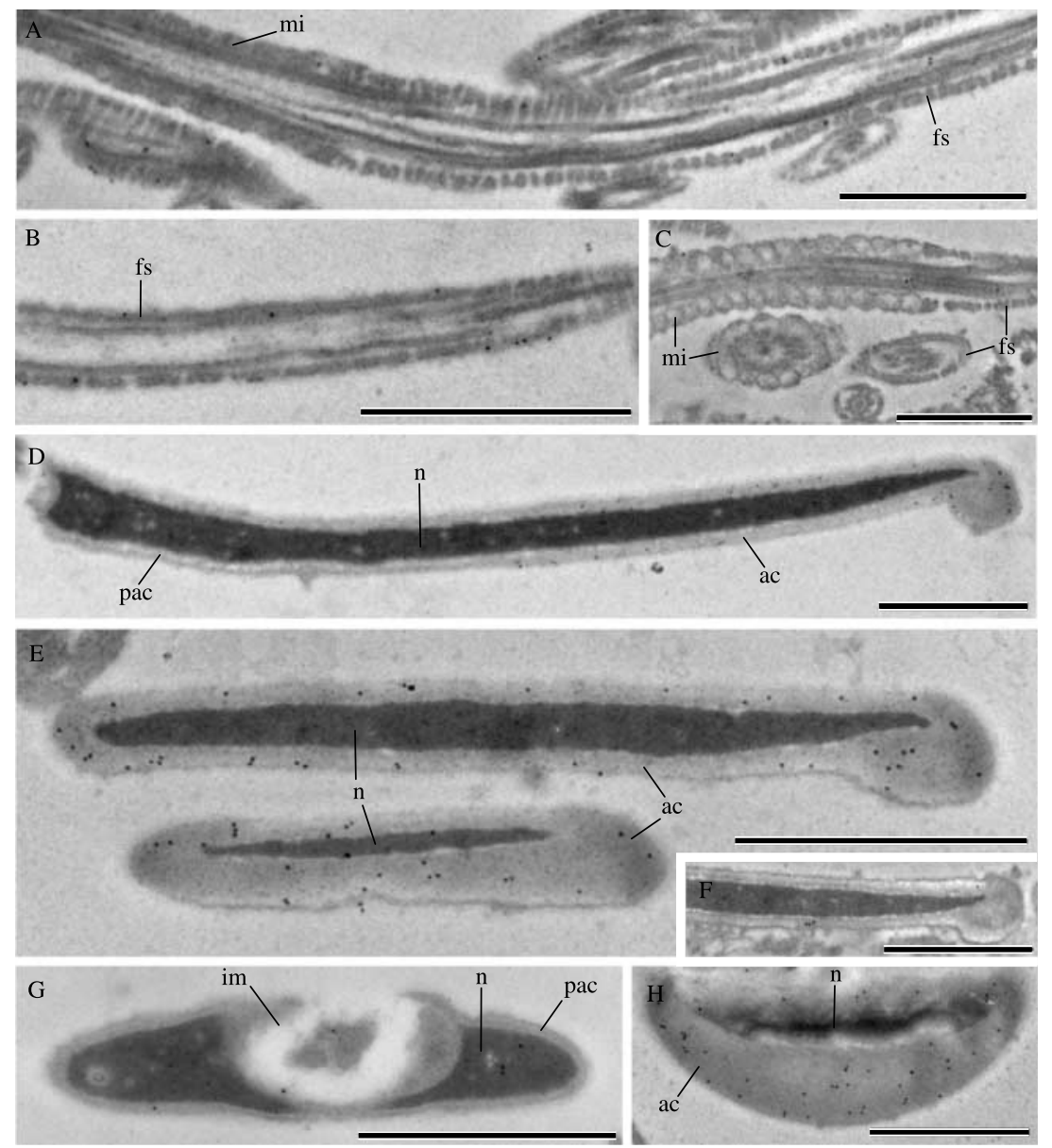

Figure 9 Ultrastructural localization of PK-S in boar sperm by immunogold electron microscopy using anti-PK-S. Although the flagellum of sperm was only slightly labelled, significantly more gold particles were found at the fibrous sheath of sperm slices exposed to anti-PK-S (A and B; see text) than in control slices treated with anti-PK-S that had been pre-incubated with the synthetic peptide of the $\mathrm{N}$-terminal sequence of PK-S (C). Anti-PK-S efficiently labelled the acrosomal area (D, E and H), while the nucleus and the postacrosomal substance ( $D$ and $G$ ) were nearly free of labels. The control with pre-incubated antibodies (F) was almost not labelled. Scale bars $=1 \mu \mathrm{m}$. ac, acrosome; df, dense fibres; fs, fibrous sheath; im, implantation fossa; mi, mitochondria; $\mathrm{n}$, nucleus; pac, postacrosomal substance.
The $\mathrm{N}$-terminal sequence $\left(\mathrm{NH}_{2}-\mathrm{TSEA}(\mathrm{M})-\mathrm{COOH}\right)$ of purified boar PK-S is certainly part of a longer extension that has been split by trypsin. This proposed sequence could resemble the $\mathrm{N}$-terminal extension of the hypothetical PK corresponding to a cDNA from bovine ileum but also the $\mathrm{N}$-terminal extensions encoded by nucleotide sequences for PK-M1 and -M2 which are, with only one exception (accession numbers BC096823 and Q4V9L8 respectively), predicted as non-translated (Fig. 10). The hypothetical bovine PK contains a lysine, and many of the predicted non-translated extensions contain an arginine directly before sequences that are similar to the PK-S extension $\left(\mathrm{NH}_{2}\right.$-TSEA-COOH). If either lysine or arginine were also present in native PK-S this would define a trypsin cleavage site and explain the tryptically generated PK-S.

Beside PK-S there exists a soluble form of PK in boar spermatozoa with kinetics similar to those of PK-M1. This soluble PK must have another $\mathrm{N}$-terminus than PK-S since it was not recognized by anti-PK-S. We assume that the soluble PK is a PK-M1 which is not $\mathrm{N}$-terminally extended and might be present in the midpiece of the flagellum where anti-PK-M1, but not
anti-PK-S brought about immunofluorescence labelling. Thus, our results indicate the existence of two different forms of PK in boar spermatozoa, a soluble PK and the bound PK-S.

\section{Localization of PK and other glycolytic enzymes in mammalian spermatozoa}

Immunofluorescence using anti-PK-M1 and anti-PK-S (Fig. 7) has shown that PK-S is localized in the principal piece of the flagellum where label was associated with the fibrous sheath as shown by immunogold labelling using anti-PK-M1 (Fig. 8) and anti-PK-S (Fig. 9). This is in line with the recent report that PK is tightly bound to purified fibrous sheath from mouse spermatozoa (Krisfalusi et al. 2006). With anti-PK-S relatively few gold labels were found at the fibrous sheath, yet their number was significantly larger than in the control. The comparatively poor gold labelling could, at least in part, be due to paraformaldehyde (PFA) fixation of the LR White-embedded spermatozoa. PFA is known to cross-link proteins and may reduce the accessibility 

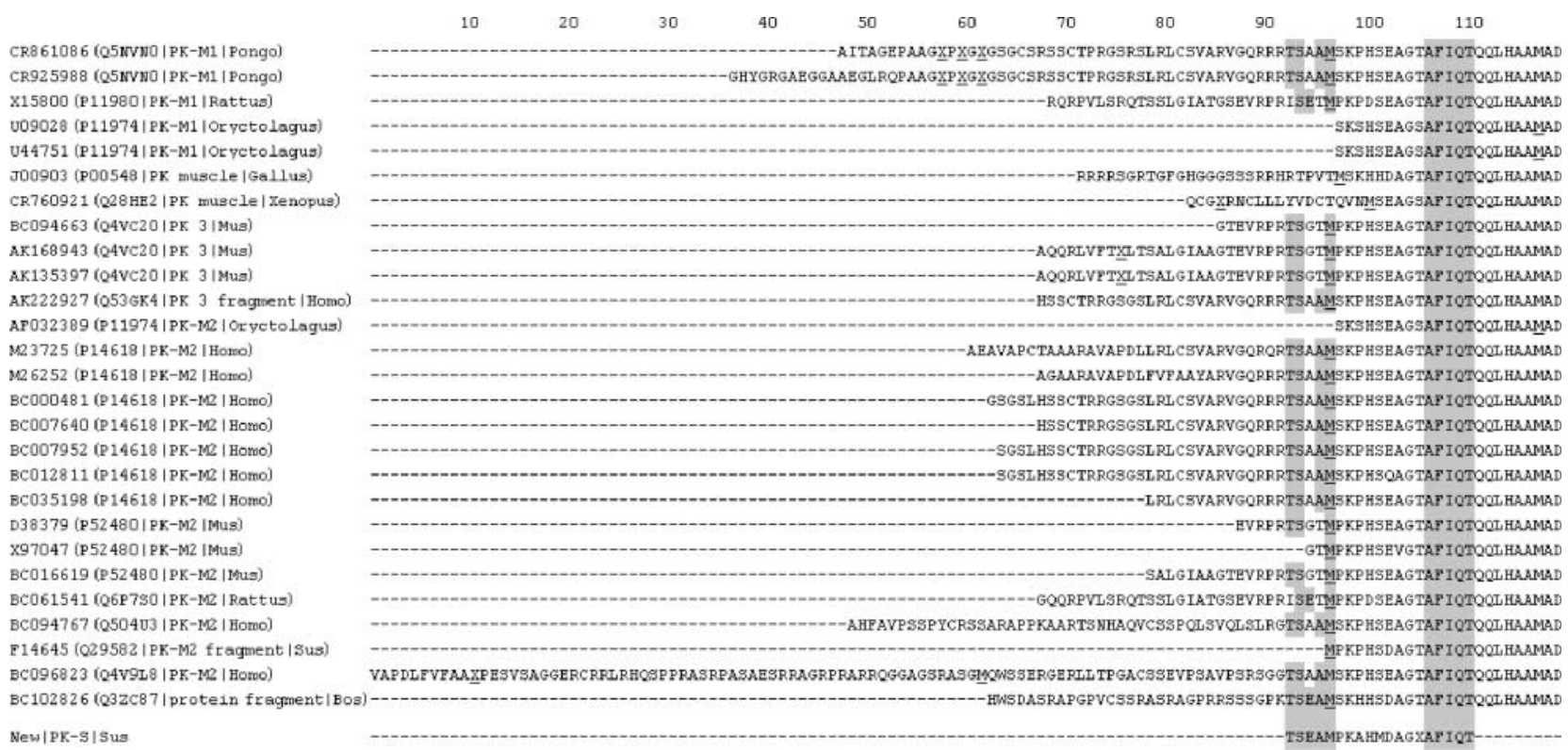

Figure 10 The N-terminus of the tryptically solubilized sperm PK-S when compared with corresponding amino acid sequences encoded in PKM mRNAs. For this comparison, PKM mRNAs were completely translated into amino acid sequences. Accession numbers of nucleotide sequences (GenBank) are given together with those of the deduced proteins (in parentheses). The N-terminus of purified PK-S (New $|\mathrm{PK}-\mathrm{S}|$ Sus; $X=$ unidentified amino acid) is shown in the last line. The first $5^{\prime}$-AUG start codon is marked as $\underline{M}$ (methionine), stop codons are represented as $\underline{X}$. PKM mRNAs often have nucleotide sequences at the $5^{\prime}$-end before the predicted start codon that encode amino acid sequences (positions 93-96; under laid) similar to the extension of PK-S. In case of PK-M1, translation is probably initiated at the usually predicted start codon AUG for methionine at position 97 (see native PK-M1 in Fig. 3; P11979 and P14618), whereas in PK-S another upstream start codon would be used. The sequence NH ${ }_{2}$-AFIQT-COOH (positions 107-111; under laid) is found in all PK-Ms and also in PK-S.

of antigens. It is not unusual that the access and conservation of antigens for their antibodies differ between various techniques (e.g. Wallimann et al. 1986, Kaldis et al. 1996). Even more important could be the fact that the antigenic epitope of anti-PK-S is only a 13 amino acid stretch of PK-S close to the part by which the enzyme is firmly attached to the fibrous sheath. This spatial arrangement could further reduce antigen accessibility for anti-PK-S when compared with anti-PK-M1 which is expected to bind to various epitopes that are more exposed to antibodies than the antigenic structure recognized by anti-PK-S.

The fact that some glycolytic enzymes are tightly bound to the fibrous sheath strongly suggests that glycolysis is structurally organized along the flagellum as already proposed by Storey \& Kayne (1975). A structural organization of glycolysis has also been proposed for somatic tissues (Arnold \& Pette 1968, Lynch \& Paul 1983, Masters et al. 1987, Srere 1987, Knull \& Walsh 1992) but binding to the cell structures show much lesser degrees of stability in these instances.

Unlike the principal piece which was labelled by both anti-PK-M1 and anti-PK-S, the midpiece of boar spermatozoa was only labelled by anti-PK-M1 but not by anti-PK-S in immunofluorescence analysis. This suggests that only the soluble sperm PK, which is not recognized by anti-PK-S, is present in the midpiece. Whether or not glycolysis is active in the midpiece of mature mammalian spermatozoa is still not clear because GAPDH has not yet been demonstrated in this part of sperm (Westhoff \& Kamp 1997, Welch et al. 2006). Interestingly, the head-midpiece junction showed PK-S staining (Fig. 7) suggesting that PK-S is bound to structures at this site. It is tempting to speculate that PK-S at this site is functionally linked to secretory pathway $\mathrm{Ca}^{2+}$-ATPase that was localized at the headmidpiece junction and might be implicated in the control of sperm $\mathrm{Ca}^{2+}$-homeostasis (for review, see Jimenez-Gonzalez et al. 2006).

Anti-PK-S substantially labelled the acrosomal area. This is evident from both immunofluorescence (Fig. 7) and immunogold labelling (Fig. 9). Immunogold particles were not found in the nucleus and the postacrosomal substance. The strong gold labelling at the acrosome is in contrast to the weak labelling of the fibrous sheath and suggests that the micro-environment of the PK-S at the acrosome differs from that at the fibrous sheath with the effect that anti-PK-S can easily reach its antigen, the proposed anchor peptide, at the acrosome but less so at the fibrous sheath. Where exactly PK-S is located at the acrosome requires further study.

PK-S is the third glycolytic enzyme located in the acrosomal area. Travis et al. (1998) found HK1-S in the membranes around the acrosome and the whole sperm head. We have recently demonstrated 6-phosphofructokinase in the acrosomal area of boar spermatozoa (Kamp et al. 2007). Interestingly, the glucose and fructose 
transporting GLUT8 was found also in this region in mouse and human sperm (Schürmann et al. 2002) and GLUT3 was reported in membranes of boar sperm head (Medrano et al. 2006). Taken together these data would suggest glycolytic activity around the acrosome. On the other hand, GAPDH has not yet been found at the acrosome (Bunch et al. 1998, Welch et al. 2006), and there is no information as to whether the beforementioned enzymes are catalytically active or inactive remnants of protein synthesis during spermatogenesis (cf. Ramalho-Santos et al. 2002, Kierszenbaum \& Tres 2004) or have other than glycolytic functions as proposed for HK (Travis et al. 1998).

\section{Kinetics and possible functions of PKs in boar sperm}

Isozymes of somatic PKs differ in their kinetic properties and this reflects tissue-specific control of glycolysis (Newsholme \& Leech 1983). Both forms of boar sperm (soluble PK and PK-S) lack activation by $\mathrm{F} 1,6 \mathrm{P}_{2}$ and inhibition by L-alanine, hence resembling muscle PK (PK-M1; Hall \& Cottam 1978) and suggesting similar functions and control of glycolysis in muscle and sperm. Our results back a report on the kinetics of structurebound PK from rabbit epididymal spermatozoa (Storey \& Kayne 1980).

Kinetic properties of enzymes can be modulated by binding of enzymes to cell structures (Masters et al. 1987, Low et al. 1993, Gutowicz \& Terlecki 2003). If binding is reversible and dependent on specific effectors, enzyme activity can thus be regulated. Boar sperm PK-S, however, is irreversibly bound to the fibrous sheath and the acrosomal area and the kinetics with respect to the substrates PEP and ADP and the potential effectors F1, $6 \mathrm{P}_{2}$ and $\mathrm{L}$-alanine were independent of whether the enzyme was bound or solubilized. This and the presence of a soluble PK with similar kinetics indicate that the novel PK-S serves the spatial arrangement of glycolytic enzymes in specific compartments rather than regulatory adaptations to sperm metabolism.

\section{Rationale for glycolysis in the principal piece and at the acrosome}

There is evidence that the fibrous sheath functions as a scaffold for spatial organization of glycolytic enzymes thus enabling ATP-production by sugar fermentation to lactate in the principal piece of the flagellum. We have proposed (Westhoff \& Kamp 1997) that glycolysis in the principal piece is important to supply ATP locally for dynein-ATPases since the mitochondria are confined to the midpiece and the phosphocreatine/creatine kinase shuttle for transport of mitochondrial energy-rich phosphate is poorly developed in mammalian spermatozoa (Kamp et al. 1996). Support for this hypothesis comes from the observations that lactate production by boar spermatozoa occurs even under normoxic conditions (Kamp et al. 2003) and is increased if sperm are stimulated to hyperactivity (unpublished results) which is vital for fertility (Yanagimachi 1994, Stauss et al. 1995, Mortimer 1997, Bedford 1998).

The role of glycolysis at the acrosome is puzzling because we do not know yet whether all glycolytic enzymes are present and active at the acrosome (see above). The presence of the transporters GLUT8 and GLUT3 together with hexokinase, 6-phosphofructokinase and PK led us speculate about possible functions of glycolysis at the acrosome. One function could be local ATP-supply for $\mathrm{Ca}^{2+}$-ATPases that keep the intracellular $\mathrm{Ca}^{2+}$ concentration low thus preventing premature acrosome reaction (cf. Feng et al. 2006). Other ATPases are also located in the acrosomal region and are important for sperm function $\left(\mathrm{Na}^{+}, \mathrm{K}^{+}\right.$-ATPase: ATP1A4, Thundathil et al. 2006; $\mathrm{H}^{+}$-ATPase: V-ATPase E1-subunit isoform, Sun-Wada et al. 2002).

In summary, our results and reports from others suggest that mammalian spermatozoa need local ATPproduction for flagellar movement and control of the acrosomal reaction. If glycolytic ATP in the principal piece powered motility, especially hyperactivity, and in the head secured proper acrosomal functioning, glycolysis will prove essential for sperm fertility in vivo.

\section{Acknowledgements}

We thank Elisabeth Sehn and Gabi Stern-Schneider for their excellent technical assistance with histochemistry and electron microscopy, Prof. Walter Stöcker for valuable discussions concerning sequence analysis. This work was supported by the Deutsche Forschungsgemeinschaft (Ka 583/7-4), and Sandra Feiden was the recipient of a scholarship (LGFG) from RheinlandPfalz. The authors declare that there is no conflict of interest that would prejudice the impartiality of this scientific work.

\section{References}

Arnold H \& Pette D 1968 Binding of glycolytic enzymes to structure proteins of the muscle. European Journal of Biochemistry 6 163-171.

Bedford JM 1998 Mammalian fertilization misread? Sperm penetration of the eutherian zona pellucida is unlikely to be a lytic event Biology of Reproduction 59 1275-1287.

Bergmeyer HU 1983 Methods of Enzymatic Analysis, 3 Verlag Chemie: Weinheim.

Bone W, Jones NG, Kamp G, Yeung CH \& Cooper TG 2000 Effect of ornidazole on fertility of male rats: inhibition of a glycolysis-related motility pattern and zona binding required for fertilization in vitro. Journal of Reproduction and Fertility 118 127-135.

Bradford MM 1976 A rapid and sensitive method for the quantitation of microgram quantities of protein utilizing the principle of protein-dye binding. Analytical Biochemistry 72 248-254.

Bunch DO, Welch JE, Magyar PL, Eddy EM \& O'Brien DA 1998 Glyceraldehyde 3-phosphate dehydrogenase-S protein distribution during mouse spermatogenesis. Biology of Reproduction $\mathbf{5 8}$ 834-841. 
Eddy EM, Toshimori K \& O'Brien DA 2003 Fibrous sheath of mammalian spermatozoa. Microscopy Research and Technique 61 $103-115$.

Feng HL, Hershlag A, Han YB \& Zheng LJ 2006 Localizations of intracellular calcium and $\mathrm{Ca}(2+)$-ATPase in hamster spermatogenic cells and spermatozoa. Microscopy Research and Technique 69 618-623.

Ford WC 2006 Glycolysis and sperm motility: does a spoonful of sugar help the flagellum go round? Human Reproduction Update 12 269-274.

Fouquet JP \& Kann ML 1994 The cytoskeleton of mammalian spermatozoa. Biology of the Cell 81 89-93.

Galantino-Homer HL, Florman HM, Storey BT, Dobrinski I \& Kopf GS 2004 Bovine sperm capacitation: assessment of phosphodiesterase activity and intracellular alkalinization on capacitation-associated protein tyrosine phosphorylation. Molecular Reproduction and Development 67 487-500.

Gevaert K, Goethals M, Martens L, Van Damme J, Staes A, Thomas GR \& Vandekerckhove J 2003 Exploring proteomes and analyzing protein processing by mass spectrometric identification of sorted $\mathrm{N}$-terminal peptides. Nature Biotechnology 21 566-569.

Gutowicz J \& Terlecki G 2003 The association of glycolytic enzymes with cellular and model membranes. Cellular and Molecular Biology Letters 8 667-680.

Hall ER \& Cottam GL 1978 Isozymes of pyruvate kinase in vertebrates: their physical, chemical, kinetic and immunological properties. International Journal of Biochemistry 9 785-793.

Hanaichi T, Sato T, Iwamoto T, Malavasi-Yamashiro J, Hoshino M \& Mizuno N 1986 A stable lead by modification of Sato's method. Journal of Electron Microscopy 35 304-306.

Jamieson BGM, Oliver SC \& Scheltinga DM 1996 The ultrastructure of the spermatozoa of squamata I. scincidae, gekkonidae and pygopodidae (Reptilia). Acta Zoologica 77 85-100.

Jimenez-Gonzalez C, Michelangeli F, Harper CV, Barratt CL \& Publicover SJ 2006 Calcium signalling in human spermatozoa: a specialized 'toolkit' of channels, transporters and stores. Human Reproduction Update 12 253-267.

Kaldis P, Stolz M, Wyss M, Zanolla E, Rothen-Rutishauser B, Vorherr T \& Wallimann T 1996 Identification of two distinctly localized mitochondrial creatine kinase isoenzymes in spermatozoa. Journal of Cell Science 109 2079-2088.

Kamp G, Büsselmann G \& Lauterwein J 1996 Spermatozoa: models for studying regulatory aspects of energy metabolism. Experientia $\mathbf{5 2}$ 487-494.

Kamp G, Büsselmann G, Jones N, Wiesner B \& Lauterwein J 2003 Energy metabolism and intracellular $\mathrm{pH}$ in boar spermatozoa. Reproduction 126 517-525.

Kamp G, Schmidt H, Stypa H, Feiden S, Mahling C \& Wegener G 2007 Regulatory properties of 6-phosphofructokinase and control of glycolysis in boar spermatozoa. Reproduction 133 29-40.

Kierszenbaum AL \& Tres LL 2004 The acrosome-acroplaxomemanchette complex and the shaping of the spermatid head. Archives of Histology and Cytology 67 271-284.

Knull HR \& Walsh JL 1992 Association of glycolytic enzymes with the cytoskeleton. Current Topics in Cellular Regulation 33 15-30.

Krisfalusi M, Miki K, Magyar PL \& O'Brien DA 2006 Multiple glycolytic enzymes are tightly bound to the fibrous sheath of mouse spermatozoa. Biology of Reproduction 75 270-278.

Laemmli UK 1970 Cleavage of structural proteins during the assembly of the head of bacteriophage T4. Nature 227 680-685.

Low PS, Rathinavelu P \& Harrison ML 1993 Regulation of glycolysis via reversible enzyme binding to the membrane protein, band 3 . Journal of Biological Chemistry 268 14627-14631.

Lynch RM \& Paul RJ 1983 Compartmentation of glycolytic and glycogenolytic metabolism in vascular smooth muscle. Science $\mathbf{2 2 2}$ 1344-1346.

Mann T \& Lutwak-Mann C 1981 Male Reproductive Function and Semen, Berlin, Heidelberg, New York: Springer-Verlag.
Marin S, Chiang K, Bassilian S, Lee WN, Boros LG, FernandezNovell JM, Centelles JJ, Medrano A, Rodriguez-Gil JE \& Cascante M 2003 Metabolic strategy of boar spermatozoa revealed by a metabolomic characterization. FEBS Letters 554 342-346.

Masters CJ, Reid S \& Don M 1987 Glycolysis-new concepts in an old pathway. Molecular and Cellular Biochemistry 76 3-14.

Medrano A, Garcia-Gil N, Ramio L, Montserrat Rivera M, FernandezNovell JM, Ramirez A, Pena A, Dolors Briz M, Pinart E, Concha II et al. 2006 Hexose-specificity of hexokinase and ADP-dependence of pyruvate kinase play important roles in the control of monosaccharide utilization in freshly diluted boar spermatozoa. Molecular Reproduction and Development 73 1179-1194.

Miki K, Qu W, Goulding EH, Willis WD, Bunch DO, Strader LF, Perreault SD, Eddy EM \& O'Brien DA 2004 Glyceraldehyde 3-phosphate dehydrogenase-S, a sperm-specific glycolytic enzyme, is required for sperm motility and male fertility. PNAS 101 16501-16506.

Mori C, Welch JE, Fulcher KD, O'Brien DA \& Eddy EM 1993 Unique hexokinase messenger ribonucleic acids lacking the porin-binding domain are developmentally expressed in mouse spermatogenic cells. Biology of Reproduction 49 191-203.

Mortimer ST 1997 A critical review of the physiological importance and analysis of sperm movement in mammals. Human Reproduction Update 3 403-439.

Muirhead H, Clayden DA, Barford D, Lorimer CG, FothergillGilmore LA, Schiltz E \& Schmitt W 1986 The structure of cat muscle pyruvate kinase. EMBO Journal 5 475-481.

Newsholme EA \& Leech AR 1983 Biochemistry for the Medical Sciences, Chichester: John Wiley \& Sons.

Noguchi T, Yamada K, Inoue H, Matsuda T \& Tanaka T 1987 The L- and R-type isozymes of rat pyruvate kinase are produced from a single gene by use of different promoters. Journal of Biological Chemistry 262 14366-14371.

Ramalho-Santos J, Schatten G \& Moreno RD 2002 Control of membrane fusion during spermiogenesis and the acrosome reaction. Biology of Reproduction 67 1043-1051.

Rodriguez-Gil J 2006 Mammalian sperm energy resources management and survival during conservation in refrigeration. Reproduction in Domestic Animals 41 11-20.

Schürmann A, Axer H, Scheepers A, Doege H \& Joost HG 2002 The glucose transport facilitator GLUT8 is predominantly associated with the acrosomal region of mature spermatozoa. Cell and Tissue Research 307 237-242.

Srere PA 1987 Complexes of sequential metabolic enzymes. Annual Review of Biochemistry 56 89-124.

Stauss CR, Votta TJ \& Suarez SS 1995 Sperm motility hyperactivation facilitates penetration of the hamster zona pellucida. Biology of Reproduction 53 1280-1285.

Storey BT \& Kayne FJ 1975 Energy metabolism of spermatozoa. V. The Embden-Myerhof pathway of glycolysis: activities of pathway enzymes in hypotonically treated rabbit epididymal spermatozoa. Fertility and Sterility 26 1257-1265.

Storey BT \& Kayne FJ 1980 Properties of pyruvate kinase and flagellar ATPase in rabbit spermatozoa: relation to metabolic strategy of the sperm cell. Journal of Experimental Zoology 211 361-367.

Sun-Wada GH, Imai-Senga Y, Yamamoto A, Murata Y, Hirata T, Wada Y \& Futai M 2002 A proton pump ATPase with testis-specific E1-subunit isoform required for acrosome acidification. Journal of Biological Chemistry 277 18098-18105.

Takenaka M, Noguchi T, Inoue H, Yamada K, Matsuda T \& Tanaka T 1989 Rat pyruvate kinase $M$ gene. Its complete structure and characterization of the $5^{\prime}$-flanking region. Journal of Biological Chemistry $2642363-2367$.

Takenaka M, Noguchi T, Sadahiro S, Hirai H, Yamada K, Matsuda T, Imai E \& Tanaka T 1991 Isolation and characterization of the human pyruvate kinase M gene. European Journal of Biochemistry 198 101-106. 
Thundathil JC, Anzar M \& Buhr MM $2006 \mathrm{Na}^{+} / \mathrm{K}^{+}$ATPase as a signaling molecule during bovine sperm capacitation. Biology of Reproduction 75 308-317.

Travis AJ, Foster JA, Rosenbaum NA, Visconti PE, Gerton GL, Kopf GS \& Moss SB 1998 Targeting of a germ cell-specific type 1 hexokinase lacking a porin-binding domain to the mitochondria as well as to the head and fibrous sheath of murine spermatozoa. Molecular Biology of the Cell 9 263-276.

Urner F \& Sakkas D 2003 Protein phosphorylation in mammalian spermatozoa. Reproduction 125 17-26.

Visconti PE, Olds-Clarke P, Moss SB, Kalab P, Travis AJ, de las Heras M \& Kopf GS 1996 Properties and localization of a tyrosine phosphorylated form of hexokinase in mouse sperm. Molecular Reproduction and Development 43 82-93.

Wallimann T, Moser H, Zurbriggen B, Wegmann G \& Eppenberger HM 1986 Creatine kinase isoenzymes in spermatozoa. Journal of Muscle Research and Cell Motility 7 25-34.

Welch JE, Schatte EC, O'Brien DA \& Eddy EM 1992 Expression of a glyceraldehyde 3-phosphate dehydrogenase gene specific to mouse spermatogenic cells. Biology of Reproduction $\mathbf{4 6}$ 869-878.

Welch JE, Brown PL, O'Brien DA, Magyar PL, Bunch DO, Mori C \& Eddy EM 2000 Human glyceraldehyde 3-phosphate dehydrogenase2 gene is expressed specifically in spermatogenic cells. Journal of Andrology $21328-338$.
Welch JE, Barbee RR, Magyar PL, Bunch DO \& O'Brien DA 2006 Expression of the spermatogenic cell-specific glyceraldehyde 3-phosphate dehydrogenase (GAPDS) in rat testis. Molecular Reproduction and Development 73 1052-1060.

Westhoff D \& Kamp G 1997 Glyceraldehyde 3-phosphate dehydrogenase is bound to the fibrous sheath of mammalian spermatozoa. Journal of Cell Science 110 1821-1829.

Williams AC \& Ford WC 2001 The role of glucose in supporting motility and capacitation in human spermatozoa. Journal of Andrology 22 680-695.

Wolfrum U \& Schmitt A 2000 Rhodopsin transport in the membrane of the connecting cilium of mammalian photoreceptor cells. Cell Motility and the Cytoskeleton 46 95-107.

Yanagimachi R 1994 Mammalian fertilization. In The Physiology of Reproduction, pp 189-317. Eds E Knobil \& J Neill. New York: Raven Press.

Received 4 October 2006

First decision 30 October 2006

Revised manuscript received 1 March 2007

Accepted 2 April 2007 